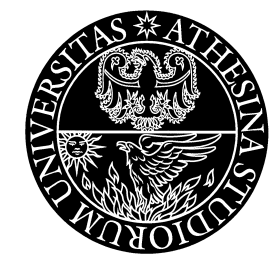

\title{
FIRMS' BANKRUPTCY AND TURNOVER IN A MACROECONOMY
}

\author{
Marco Bee \\ Giuseppe Espa \\ Roberto Tamborini
}

Discussion Paper No. 3, 2002 
The Discussion Paper series provides a means for circulating preliminary research results by staff of or visitors to the Department. Its purpose is to stimulate discussion prior to the publication of papers.

Requests for copies of Discussion Papers and address changes should be sent to:

Prof. Andrea Leonardi

Dipartimento di Economia

Università degli Studi

Via Inama 5

38100 TRENTO ITALY 


\title{
Find brikptyadunoeina nacouony
}

\author{
Marco Bee \\ IntesaBci Bank \\ Risk Management, Development \& Research \\ Via Verri 4, 20121 Milano, Italy \\ Phone: +39-02-88502121, Fax: +39-02-88507590 \\ E-mail: MARCOBEE@INTESABCI.IT
}

\section{Giuseppe Espa}

University of Trento,

Via Inama 5, 38100 Trento, Italy,

Phone +39-0461-882157, Fax. 0461-882101

E-mail: GESPA@RISC1.GELSO.UNITN.IT

\section{Roberto Tamborini}

University of Trento, Department of Economics,

Via Inama 5, 38100 Trento, Italy,

Tel. 0461-882228, Fax. 0461-882222

E-mail: RTAMBORI@RISC1.GELSO.UNITN.IT

Workshop on Economics and Hetereogeneous Interacting Agents

Abdus Salam International Centre for Theoretical Physics (ICTP)

Trieste (Italy) 30 May - 1 June 2002

\footnotetext{
*This paper is part of the research project "Sources, evaluation and integrated management of risk in non financial firms" (2000) co-financed by MURST and the University of Trento. The authors are grateful to Kumaraswamy Velupillai and Axel Leijonhufvud for their comments to earlier drafts.
} 


\section{FIRMS' BANMKRUPTCY AND TURNOVER IN A MACROECONOMY}

\section{Itadition}

The so-called "rational expectations revolution" that has completely reshaped economic theory and general equilibrium theory in the last two decades has, incidentally, brought earlier ideas on the crucial importance of agents' knowledge, information and beliefs to the forefront forcing modern followers of those ideas to reconsider them far more deeply, systematically and rigorously (Arrow (1986), Hahn (1977, 1981)). It soon turned out that when agents act upon beliefs and engage in out-of-equilibrium learning, heterogeneity (of beliefs) and selfreferentiality (of market outcomes) ${ }^{1}$ may determine large sets of multiple equilibria, and of dynamic paths of the economy, which collapse onto the unique RE competitive general equilibrium only under a number of restrictive conditions (Frydman-Phelps (1983), Kirman (1987, 1992), Pesaran (1987), Bray-Kreps (1986), Marcet-Sargent (1989), Arthur (1992)).

The fact that expectations, let alone out-of-equilibrium beliefs and learning, may give rise to mistakes in decision-making ${ }^{2}$, has however been much less considered, and the implications of this fact at the individual as well as systemic level even less investigated. Rational (in a broad sense) expectations are rooted in knowledge, and knowledge is an evolving-adaptive mental representation of the external

\footnotetext{
${ }^{1} \mathrm{~A}$ self-referential system is such that the actual value of a variable is a function of its expected value in the population, which is a function of the distribution of beliefs in the population. See e.g. Pesaran (1987) and Frydman (1983) for introductory treatment.

${ }^{2} \mathrm{~A}$ fact quite clear even under the strong RE hypothesis, which states that asymptotically decisions are not wrong in a systematic manner but does not state that they are systematically right (Lucas (1981)).
} 
environment (e.g. Lucas (1987), Arthur (1992), Holland (1975)). Trials and errors are an integral part of the evolutionary-adpative process that builds up our knowledge (Holland (1975)). Even in the most formal models of this process, from Bayesian to stochastic recursive ones (e.g. Bray-Kreps (1986), Marcet-Sargent (1989)), errors paly a crucial informative role in steering the process itself. Yet errors not only bring benefits but also costs. In particular, models of expectations formation in economics usually do not include the possibility that decision-makers may fail, that failures are generally costly, that they may happen to be fatal, and that the birth-death turnover of agents may change the environment structure. It is surprising that economic theorists have tended to overlook these facts since "paying for one's mistakes" is a building block of the capitalist way of living, of market ethics and organization, and of Darwinian evolutionary explanations of individual rationality and market efficiency (Alchian (1950), Friedman (1949)). Hence, the possibility of costly errors should have consequences on individual economic behaviour as well as on aggregate outcomes of individual decisions ${ }^{3}$. Here we concentrate in particular on one extreme

${ }^{3}$ At the individual level, the possibility of costly errors is only apparently dealt with by the standard expected-utility approach to risk aversion. This approach may properly explain how much expected utility an individual is ready to forego in order to receive a compensation in all future states that entail a utility loss to him/her. Yet ex-ante utility equalization across states is a peculiar representation in that it disregards other important attributes of rational behaviour in the face of costly errors. Consider the case pointed out by Hicks (1951) and Roy (1952) at the dawn of modern portfolio theory. An investor faces a small probability of a large loss: if the related expected-utility loss is "very" large or "disastrous", no compensation may exist so that the expected-utility approach easily breaks down. Bankruptcy is a leading example of such extreme events which is nonetheless quite common in economic life and is commonly taken as a risk by businessmen. The objection that in large (in the limit complete) markets by virtue of diversification and risk sharing no one in fact bets a "very" large share of one's wealth on extreme events does not lead us very far. 
consequence of economic errors that nonetheless lies at the very core of business life: bankruptcy.

By bankruptcy we simply mean a firm' s foreclosure and exit from the market. We speak of bankruptcy because firms in our model are indebted with a bank. Technically, this event may take different forms that are irrelevant for this paper' $\mathrm{s}$ purposes. What is essential is that a firm may be forced to leave the market as a consequence of wrong decisions, where a firm is identified by its "software", not its "hardware"4. Although we model firms as decision makers that discount the probability of this event, our interest is not for the consequences of bankruptcy at the firm level (on which an enormous literature exists involving law, buisiness finance and business administration) but at the economy level, particularly in a general-equilibrium perspective, where the literature is instead scant (e.g. Hahn (1977), Greenwald-Stiglitz (1988, 1990, 1993), Hahn-Solow (1995)). How does an economic system work when the fact that the firms' population displays a certain birthdeath rate is introduced?

We focus on three moments when the problem arises. When forming expectations under uncertainty, firms' rational decision makers (entrepreneurs) should discount the probability of making fatal mistakes that lead to bankruptcy. Moreover, only survivors have a

As a matter of fact, markets are far from being complete, especially in consideration of innovative investments. Moreover, most businesses are run by undiversified owners while even in quoted public companies important classes of stakeholders (such as managers and employees) are "locked in" for a large share of their permanent income (a fact worsened by current practices like stock options and Enron-style finance). In all these and similar cases, rational risk-taking has to be the result of calculations and decisions that differ from those prescribed by the expected-utility approach. Research in this field, which is complementary to the work reported in this paper, is not presented here.

${ }^{4}$ Hence takeovers may be an alternative way to introduce the same event. 
chance to learn and improve over their previous decisions. Finally, at any point in time the agents' population in an economy consists of "learned" survivors from the past and "ignorant" newcomers that take over failed agents; hence we expect the aggregate outcome at that point time to differ from the one given by a uniform population, and we expect it to evolve over time in a way that differs from the one traced out by the asymptotic "free lunch" error processing à la Lucas-Sargent.

We address these problems by means of a model whose main features are:

- heterogenous population (i.e. heteregenous beliefs about the relevant variable, the price level of output)

- $\quad$ sequential decision making

- self-referentiality

- a positive probability of bankruptcy for firms at each point in time

Our model draws on Greenwald and Stiglitz $(1988,1993)$. In each period $t$ there exists a constant population of a continuum of agents (workers and entrepreneurs) which live for two periods, and a government inclusive of a central bank that live forever. Agents consume one single good which is distributed as endowment at birth and can also be produced by means of a technology requiring 1 period of production regardless of the scale, with one single input (labour) with decreasing return. All transactions in the economy should take place against money according to the so-called "Clower rule".

Hence, entrepreneurs who want to run a firm should receive credit from a bank to pay the wage bill. We straightforwardly assume a single central bank which issues standard debt contracts with the exclusion of any risk on the part of the bank. This type of debt contract is a crucial element in our picture since it introduces a bankruptcy clause in case of insolvency, and hence the selction mechanism in the population of firms.

This mechanism is not due to exogenous shocks like in Greenwald-Stiglitz' s original models but it is "endogenous" in the sense that it is the direct consequence of entrepreneurs' heterogeneous beliefs 
on the price generating machanism after observing a common external signal given by the rate of growth of money supply. These beliefs generate a continuum of individual expected, or better "conjectured", prices to which we impose the shape of a uniform distribution. Individual expected prices are strictly private information. We identify a given generation of entrepreneurs by three population' $s$ parameters: the mean value, the dispersion and the tolerance level of their expected prices. Since individual expected prices are private information, the popolution' s parameters are unknown to individual agents. Then we show that, at the market-clearing price in $t+1$, there will go bankrupt all the $t$-th generation' $\mathrm{s}$ entrepreneurs whose expected price exceeds a threshold value which is a function of the three population' $s$ parameters. In other words, we might say that whether a firm fails or not in this economy only depends on relative expected prices.

As far as a single generation is concerned, we study:

- the price determination mechanism under firms' failure

- the ensuing relationship between the price level and the rate of money supply in comparison with its "fundamental" value that would result under homogeneous rational expectations

- the relationship between the price level and the populations' parameters, in particular the mean value of expected prices

- the relationship between the population's parameters and the bankruptcy probability

We then move towards the dynamics of our model economy as bankrupt firms are driven out of the market and newcomers enter. Reshuffling of population in each period has two consequences: first, it preserves hetereogeneity, second, it changes the economy' s structure for incumbent firms. Therefore,

- the process driving changes in the price level over time, for a given money growth rate, is fully determined by the population' $\mathrm{s}$ dynamics and, under our assumptions, is totally hidden from individual agents' view 
- successful beliefs in one period may no longer be such in the subsequent period

At the present stage of development of our research, we limit ourselves to the analysis of the implications of self-referentiality under the population dynamics generated by exits and entries with no specific assumptions on learning. Newcomers that take over bankrupt firms are characterized by beliefs drawn from the same uniform distribution as the previous generation, whereas we substantially rule out incumbents' learning by assuming that all entrepreneurs in solvent firms do not revise the previous generation' s successful belief. This implies that previous generations' successful beliefs have a growing weight, and that the distribution of beliefs is no longer uniform, as the population evolves over time. We then study

- the dynamics and the asymptotic properties of this evolution mechanism

- its consequences on price level determination and bankruptcy probability over time

- and in particular whether in the long run bankruptcies tend to disappear or to settle down in a "structural" limit-level.

\section{7enciterovy}

We consider a sequential monetary economy of production and consumption. Time is introduced in discrete periods indexed by $t$. In each period $t$ there exists a constant population of a continuum of agents $A$ which live for two periods, and a government $G$ inclusive of a central bank $B$ that live forever. Agents consume one single good which is distributed as endowment at birth and can also be produced by means of a technology requiring 1 period of production regardless of the scale with one single input (labour) with decreasing return. All transactions 
in the economy should take place against money according to the socalled "Clower rule"5.

\subsection{Agents and institutions}

- Each agent in the population, $a \in A$, has a lifetime horizon of two periods: one period of activity $(t)$, and one period of retirement $(t+1)$; at birth each agent receives a given quantity of the consumable good as endowment, which is fixed for all $a$ and $t$

- There are two classes in the population that differ in their endowments: the "poor" have an endowment just equal to the subsistance level, $\underline{x}$; the "rich" have a quantity of the consumable good that exceeds $\underline{x}$

- Endowments predetermine the agents' activity choices: the poor, if they wish to consume in both periods of life, can only be workers, $a=w$, $w \in A$, with $x_{w}=\underline{x}$; the rich may choose to be entrepreneurs, $a=j, j \in A$, with $x_{j}>\underline{x}$; for simplicity and without loss of generality we assume that the measure of the two classes of agents, $W$ and $J$ respectively, is equal and constant over time

- All agents are risk neutral.

The poor' s choice is constrained by their endowent which is just sufficient to their subsistance in the first period. If they wish to consume in the second period they have to sell all their labour force in the labour market, earn a wage, and transfer it to the second period for consumption $^{6}$. The rich may choose to run a firm by transforming the

${ }^{5}$ We assume this rule as an insititutional fact which is typical of monetary economies, and which we do not wish to explain here. We are instead interested in investigating the consequences of this fact as concerns the working of the economy.

${ }^{6}$ For simplicity we do not model the possible choices of workers concerning work and leisure and the time distribution of consumption of wage earnings. 
excess of their endowment over subsistance in the first period into a production means in the way that will be explained below. The incentive for the rich to become entrepreneurs is given by the prospect of adding their firm' s second-period profit to their total resources. Given riskneutrality, any positive expected profit is sufficient for the rich to choose to be entrepreneurs. This choice is also Pareto improving since it allows the poor to become workers and to consume in the second period.

Pareto-improving transactions between the two classes in the economy require that the labour market opens at each $t$ when newborn workers wish to exchange labour for wage with newborn entrepreneurs, and the output market opens at $t+1$ where the retired workers wish to exchange their wage earnings for consumption with terminal firms. Given Clower rule, workers want to be paid in money at $t$ and firms want to be paid in money at $t+1$. Consequently, entrepreneurs at $t$ need to collect the money equivalent of wages. This operation is made possible by opening the credit market at each $t$.

\subsection{The economy at work}

The working of our sequential economy is described in figure 1 and explained below.

\section{[Figure 1]}

More specifically, the sequence of decisions in the economy results as follows.

In $t$ a) each firm $j$ plans the output level $y(t)_{j t+1}$

b) it employs the relevant labour input $n_{j t}$, at the market nominal wage rate $s_{t}$, and borrows the resulting wage bill $s_{t} n_{j t}$ at the nominal gross rate $\left(1+r_{t}\right) \equiv R_{t}$;

c) each worker $w$ offers 1 unit of labour in fixed amount at the nominal rate $s_{t}$, works and consumes his/her initial endowment $\underline{x}$, and saves income $s_{t}$ at the rate $R_{t}$ for

Modelling thse choices would only add further parameters which are not important in our context. 
consumption in $t+1$

d) the bank lends to each entrepreneur the wage bill $s_{t} n_{j t}$ and accepts from each worker the deposit $s_{t}$, both at the rate $R_{t}$

In $t+1$ : a) each retired worker consumes his/her saving $s_{t} R_{t}$

b) each firm sells output at the market price $p_{t+1}$ and may

be solvent or insolvent with the bank (see below)

As is clear from the above time structure of transactions, and in force of the Clower rule, a "device" is needed in order to transform the illiquid excess endowment of entrepreneurs into money. This function is performed by banks ${ }^{7}$. The central bank is the sole banking institution in the economy and performs three functions:

- it issues fiat money according to the Clower rule

- it acts as commercial bank, lending to entrepreneurs and offering deposit services to workers, at the terms that will be specified below

- it finances public expenditure.

We straightforwardly assume a standard debt contract with the exclusion of any risk on the part of the bank ${ }^{8}$. This type of debt contract is a crucial element in our picture since it introduces a bankruptcy clause in case of insolvency, and hence the selction mechanism in the population of firms. Therefore, each entrepreneur can obtain in $t$ a loan of size $B_{j t}=s_{t} n_{j t}$ from a bank, for 1 period, at the rate $R_{t}$ provided that:

\footnotetext{
${ }^{7}$ This the same function attributed to banks in Kiyotaki and Moore' s (1997) economy.

${ }^{8}$ The standard debt contract (see e.g. Freixas-Rochet (1998)) is now a workhorse in bank-firm models like the present one, though we do not prove that this kind of contract is optimal in our setup. In fact, what we simply need for our purposes is any financial arrangement which shifts the bankruptcy risk onto the firm, since this is the way through which forecast errors beyond a critical magnitude produce selection in the population of firms. For the same reason, we also wish to exclude that the bank bears any risk.
} 
- the entrepreneur' $\mathrm{s}$ excess endowment $x_{j}-\underline{x}$, is given as collateral

- the entrepreneur is commited to the following repayment scheme in $t+1$ :

if $p_{t+1} y(t)_{j t+1} \geq B_{j t} R_{t}$, the firm is solvent, pays $B_{j t} R_{t}$ to the bank, and the entrepreneur reappropriates his/her collateralized endowment

if $p_{t+1} y(t)_{j t+1}<B_{j t} R_{t}$, the firm is insolvent, the bank seizes the firm' s revenue and possibly the collateral up to

$$
p_{t+1}\left(x_{b j t+1}+y(t)_{j t+1}\right)=B_{j t} R_{t}+p_{t+1} b
$$

where $b$ are fixed bankruptcy costs in real terms, and the firm is declared bankrupt and exits from the market. ${ }^{9}$

Note that the above repayment scheme implies that the entrepreneur faces two possibile lifetime consumption possibilities:

$$
\begin{array}{ll}
\pi_{j t+1}+x_{j} & \text { in case of solvency } \\
x_{j}-x_{b j t+1} & \text { in case of bankruptcy }
\end{array}
$$

where $\pi_{j t+1}$ is the net real profit given by

$$
\pi_{j t+1}=y(t)_{j t+1}-B_{j t} R_{t} / p_{t+1}
$$

If we take the real value of debt as of $t, B_{j t} / p_{t}$, substitute the expression of $B_{j t}$, and define $\underline{s}_{t} \equiv s_{t} / p_{t}$ as the real wage rate, $q_{t} \equiv p_{t+1} / p_{t}$ as the growth factor of prices (inflation rate for short), the net real profit can be re-written as follows:

$$
\pi_{j t+1}=y(t)_{j t+1}-\underline{s}_{t} n_{j t} R_{t} / q_{t+1}
$$

where $\underline{s}_{t} n_{j t}$ is the real wage bill and $R_{t} / q_{t+1}$ the (gross) real interest rate.

${ }^{9}$ Note that, as a consequence, it must be that $x_{j}-\underline{x} \geq x_{b j t+1}$, which we assume is always satisfied. 


\section{Stis Teatityere}

We first study the competitive general equilibrium solution of the above model economy in the certainty case. Given the sequence structure of decisions, certainty requires perfect foresight. In this case, the solution is trivial, amounting to a simple exemplification of Say' $s$ Law with money, and we only give it as a reference point. profit 10 :

Each entrepreneur' $\mathrm{s}$ objective is to maximie the net real

$$
\max \pi_{j t+1}=y(t)_{j t+1}-\underline{s}_{t} n_{j t} R_{t} / q_{t+1}
$$

given the production function

$$
y(t)_{j t+1}=n^{\alpha}{ }_{j t} \quad \alpha \in[0,1)
$$
function

The choice variable is $n_{j t}$ and the optimal labour input is the

$$
n_{j t}=\left(\alpha q_{t+1} \underline{s}_{t} R_{t}\right)^{1 / 1-\alpha}
$$

Since each worker offers 1 unit of workforce inelastically, $n_{j t}$ is also the size of employment by firm $j$, and is equal for all $j$. Aggregate labour demand $N_{t}$ is therefore $n_{t}$ times the measure of the entrepreneurs' class $J$. Total employment cannot exceed the measure of the workers' class, $W$. Since $W=J$, the labour market determines the real wage rate $\underline{s}_{t}$ at full employment is such a way that

$$
\begin{aligned}
& \left(\alpha q_{t+1} / \underline{s}_{t} R_{t}\right)^{1 / 1-\alpha}=1 \\
& \underline{s}^{*}{ }_{t}=\alpha q_{t+1} / R_{t}
\end{aligned}
$$

which also implies $n_{j t}=1, y(t)_{j t+1}=1$ for all $j$.

${ }^{10}$ Which, in our setup, is equivalent to maximizing lifetime consumption possibilities. 
The bank pegs the nominal interest rate, and hence $R_{t}$, lends $\underline{s}^{*}{ }_{t} p_{t} W$ to entrepreneurs and receives the same amount as workers' deposits; hence it always achieves balance-sheet equilibrium.

In $t+1$, aggregate full-employment output on sale is $Y(t)_{t+1}=J=$ $W$. Aggregate consumption consists of retired workers' and retired entrepreneurs' consumption. A worker' s consumption is given by his/her real saving from previous period,

$$
\begin{aligned}
c(t)_{w t+1} & =\underline{s}^{*}{ }_{t} p_{t} R_{t} / p_{t+1} \\
& =\underline{s}^{*}{ }_{t} R_{t} / q_{t+1}
\end{aligned}
$$

which is therefore equal for all workers. Hence, substituting the value for $\underline{s}^{*}{ }_{t}$, workers' aggregate consumption is

$$
C(t)_{w t+1}=\alpha W
$$

In force of perfect foresight, entrepreneurs realize planned maximum real profits after repaying debt, so that their aggregate (market) consumption is

$$
\begin{aligned}
C(t)_{j t+1} & =Y(t)_{t+1}-\underline{s}^{*}{ }_{t} R_{t} W / q_{t+1} \\
& =(1-\alpha) W
\end{aligned}
$$

It is immediate to notice that, due to the transfer of labour income to $t+1$ in the form of savings, Say' $\mathrm{s}$ Law holds int +1 . This, as is well-known, implies that the output market always clears at any price level.

To determine $p_{t+1}$ a monetary equation is introduced on the grounds that, under the Clower Rule, the total (outside) money stock available in each $t$ must exactly meet the demand for money, which in this case amounts to the money value of output with unit velocity, i.e.:

$$
\begin{aligned}
M_{t+1} & =Y(t)_{t+1} p_{t+1} \\
& =W p_{t+1}
\end{aligned}
$$

Of course, classical (super)neutrality holds. In fact, let the central bank create money at a gross rate $\omega_{t+1}=M_{t+1} / M_{t}$. Since in equilibrium $M_{t}=$ $W p_{t}$, dividing both sides of equation (3.7) by $M_{t}$, we obtain 


$$
\omega_{t+1}=p_{t+1} / p_{t}=q_{t+1}
$$

that is to say, the price level grows at the growth factor of money.

\section{Stisubatatyadâlus}

In this section we introduce uncertainty. The only relevant uncertainty in the model of section 3 is entrepreneurs' uncertainty at time $t$ over the inflation rate at time $t+1$, which affects firms' profit maximization given by problem (3.1).

In this problem, $q_{t+1}$ has to be replaced by an expectation that is uncertain. As to expectation formation, we assume bounded rationality (in Pesaran' s sense (1987)), that is,

(A1) Each agent knows the variable' s generation process but does not know its exact specification

A fundamental reason behind this assumption is that the "true" generating process is self-referential (i.e. it may differ from (3.8)) as will become clear in due course.

\subsection{Heterogeneous individual conjectures}

We translate the previous assumption into our model by associating to each entrepreneur born at $t$ an individual specification of equation (3.8) in the following "conjectural" form

$$
p^{e}{ }_{j t+1}=\omega_{t+1} u_{j t}
$$

where $\omega_{t+1}$ is known with certainty (e.g. is announced by the central bank in advance), and $u_{j t}$ represents the individual conjecture about the relationship between the growth factor of money and the inflation rate. Note that the "theoretical value" of $u_{j t}$ is 1 .

The following additional assumptions complete our characterization of entrepreneurs' individual beliefs. 
(A2) Individual conjectures $u_{j t}$ in each period' $\mathrm{s}$ newborn population of entrepreneurs are a continuous random variable $U_{t}$ uniformly distributed in the population, with strictly positive support $u_{j t} \in\left[u^{\mathrm{L}}{ }_{t}, u^{\mathrm{H}}{ }_{t}\right]$, and density

$$
f\left(u_{j t}\right)= \begin{cases}\left(u_{t}^{\mathrm{H}}-u_{t}^{\mathrm{L}}\right)^{-1} & u \in\left[u_{t}^{\mathrm{L}}, u_{t}^{\mathrm{H}}\right] \\ 0 & \text { elsewhere }\end{cases}
$$

Consequently, from (4.1) individual expectations $q_{j t+1}^{e}$ also follow a continuous uniform distribution, with strictly positive support between the lower bound $q^{e \mathrm{~L}}{ }_{t+1}=\omega_{t+1} u_{t}^{\mathrm{L}}$ and the upper bound $q^{e \mathrm{H}_{t+1}}=$ $\omega_{t+1} u_{t}^{\mathrm{H}}$, and with mathematical expected inflation rate in the economy

$$
\begin{aligned}
q_{t+1}^{e} & =\mathrm{E}_{t}\left(p^{e}{ }_{j t+1}\right) \\
& =\omega_{t+1} \mathrm{E}_{t}\left(u_{j t}\right) \\
& =\omega_{t+1}\left(u^{\mathrm{H}}{ }_{t}+u^{\mathrm{L}}{ }_{t}\right) / 2
\end{aligned}
$$

(A3) Each entrepreneur, in turn, holds his/her inflation expectation with a "tolerance interval" around $q_{j t+1}^{e}$ of equal module $\left|\delta_{t}\right|$, i.e.:

$$
\begin{aligned}
& q^{e \mathrm{~L}_{j t+1}}=q^{e}{ }_{j t+1}-\delta_{t} \\
& q^{e \mathrm{H}_{j t+1}}=q^{e_{j t+1}}+\delta_{t}
\end{aligned}
$$

(A4) Individual conjectures $u_{j t}$, and hence individual inflation expectations $q_{j t+1}^{e}$, are private non-observable information.

Note that, as a consequence, each individual entrepreneur does not know the distribution of inflation expectations in the population,

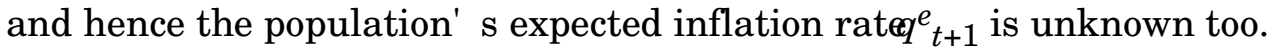

Now we can completely identify a population of firms in $t$ with its own three parameters:

- $\delta_{t}$, tolerance

- $\mu_{t}=\left(\mathrm{u}_{t}^{\mathrm{H}}+\mathrm{u}_{t}{ }_{t}\right) / 2$, expected value of conjectures $u_{j t}$

- $\Delta_{\mathrm{t}}=\mathrm{u}_{\mathrm{t}}^{\mathrm{H}}-\mathrm{u}_{\mathrm{t}}^{\mathrm{L}}$, dispersion of conjectures $u_{j t}$ 


\subsection{Individual decisions}

Uncertainty, as defined above, modifies the entrepreneur' $\mathrm{s}$ decision problem. First, note that so far we have introduced uncertainty in a "subjective" form since each entrepreneur holds his/her inflation expectation within a range of values (assumption (A3)). Rationally, this uncertainty has to be associated with a positive probability of bankruptcy. In fact, assumption (A3) implies that the entrepreneur expects that the actual inflation rate $q_{t+1}$ may turn out to be different from his/her individual expectation $q^{e}{ }_{j t+1}$, and it may happen to be too low for the firm to be solvent with the bank.

We first give a measure of this "subjective" bankruptcy probability implied by assumption (A3). From the debt contract described in section 2 , it follows that a firm is insolvent when its net real profit is negative or

$$
q_{t+1}<\underline{s}_{t} n_{j t} R_{t} / y(t)_{j t+1} \equiv v_{j t}
$$

i.e. if the actual inflation rate is lower than its real debt-output ratio, that we define $v_{j t}$.

Now let us define the bankruptcy probability of the firm as

$$
\phi_{j t} \equiv \operatorname{Prob}\left(q_{t+1} \leq v_{j t}\right)
$$

Since assumption (A3) describes the distribution of the entrepreneur' $\mathrm{s}$ price expectation, the measure of (4.4) implied by (A3) is:

$$
\begin{aligned}
F_{j t}\left(v_{j t}\right) & =\left(v_{j t}-q^{e \mathrm{~L}_{j t+1}}\right)\left(q^{e \mathrm{H}_{j t+1}}-q^{e \mathrm{~L}_{j t+1}}\right)^{-1} \\
& =1 / 2-\left(q_{j t+1}^{e}-v_{j t}\right) / 2 \delta_{t}
\end{aligned}
$$

Therefore, the subjective bankruptcy probability of each firm,

- increases with $v_{j t}$ (a high real debt-output ratio makes insolvency more likely)

- decreases with $q^{e}{ }_{j t+1}$ (a higher expected inflation rate makes insolvency less likely)

We now examine the optimal output and employment decision. Under debt contract, the firm' s problem is to $\operatorname{choosen}_{j t}$ so as to 


$$
\max \pi^{e}{ }_{j t+1}=y(t)_{j t+1}-\underline{s}_{t} n_{j t} R_{t} / q^{e}{ }_{j t+1}-F_{j t}\left(v_{j t}\right) b
$$

The f.o.c. is the soluton of the following equation

$$
\alpha n_{j t}{ }^{\alpha-1}-(1-\alpha)\left(b \underline{s}_{t} R_{t} / 2 \delta\right) n_{j t}{ }^{-\alpha}-s_{t} R_{t} / q^{e}{ }_{j t+1}=0
$$

In order to obtain a closed-form solution we impose $\alpha=0.5$. The optimal labour input results:

$$
n^{*}{ }_{j t}=\left[\left(q^{e}{ }_{j t+1} / 2 \underline{s}_{t} R_{t}\right)-b / 4 \delta_{t}\right]^{2}
$$

The first addendum is the same as in the case of certainty. Therefore, we conclude that

- uncertainty reduces each firm's labour demand proportionally to the marginal expected bankruptcy cost $b / 4 \delta_{t}$

- each firm's labour demand differs by the individual expected inflation rate $q^{e}{ }_{j+1}$.

The marginal expected bankruptcy cost $b / 4 \delta_{t}$ (the increase in the expected bankruptcy cost due to an increase in planned output, employment and debt) is obviously increasing in the direct bankrupty cost $b$ while is decreasing in $\delta_{t}$ up to the "certainty equivalent" value of 0 as $\delta_{t} \rightarrow \infty$. We interpret this as a measure of the "degree of tolerance" of forecast errors. For instance, if $\delta_{t}$ is large the entrepreneur operates under less strict forecast precision, and his/her labour demand is more buoyant ${ }^{11}$.

\subsection{Aggregate results}

We have seen above that, owing to different individual expected inflation rates, labour demand is now different across firms. For each firm to employ one unit of labour force so as to ensure full employment

${ }^{11}$ Think of $\delta_{t}$ as the diameter of the target in a rifle contest. The economic meaning of $\delta_{t}$ is analogous to the degree of risk aversion, though we derive it as an attitude towards errors rather than as a property of the utility function. 
as in section 3, each firm should be willing to pay the individual real wage rate

$$
\begin{aligned}
& \underline{s}^{*}{ }_{j t}=\beta_{t} q^{e}{ }_{j t+1} / 2 R_{t} \\
& \left.\beta_{t}=\left(1+b / 4 \delta_{t}\right)^{-1} \in\right] 0,1[
\end{aligned}
$$

so that the mathematical expectation of the real wage rate in the economy is

$$
\mathrm{E}\left(\underline{s}^{*}{ }_{j t}\right)=\beta_{t} \mu_{t} / 2 R_{t}
$$

Hence, ceteris paribus, uncertainty reduces $\mathrm{E}_{t}\left(\underline{s}_{j t}^{*}\right)$ relative to the market value $\underline{s}_{t}^{*}$ under certainty by the factor $\beta_{t}$. This factor captures the effect of the marginal expected bankruptcy cost. Since $b / 4 \delta_{t}>0$, generally $\beta_{t}<1$, and it decreases (increases) as $b / 4 \delta_{t}$ increases (decreases) (see above for the interpretation of $\delta_{t}$ ).

In $t+1$, aggregate output on sale is again $Y(t)_{t+1}=W$. However, as is intuitive, bankruptcies break Say' $\mathrm{s}$ Law since bankrupt entrepreneurs cannot participate in market consumption. In Keynesian words, bankruptcies operate as an endogenous source of effective demand deficiency; since output is fixed by previous period' $\mathrm{s}$ decisions, the price level should adjust to clear the output market.

Let us first consider retired workers' consumption. This is given by their real savings. Suppose that the announced increase in money supply is realized in the form of a government per-capita monetary transfer to retired workers $m_{w t+1}$ entirely financed by printing money, so that $M_{t+1}=M_{t}+m_{w t+1} W=\omega_{t+1} M_{t}$, or $m_{w t+1} W=M_{t}\left(\omega_{t+1}-1\right)$. Consequently, the retired workers' real savings int +1 are equal to the real value of previous period' $\mathrm{s}$ deposits and the money transfers and therefore

$$
C(t)_{w t+1}=\left[p_{t} \mathrm{E}\left(\underline{s}_{j t}^{*}\right) R_{t} W+M_{t}\left(\omega_{t+1}-1\right)\right] / p_{t+1}
$$

Since $M_{t}=Y(t-1)_{t} p_{t}$, or $M_{t}=W p_{t}$, and considering the expression of $\mathrm{E}\left(\underline{s}_{j t}^{*}\right)(4.9)$, we can also write

$$
C(t)_{w t+1}=\left(\mu_{t} \beta_{t} / 2+\omega_{t+1}-1\right) W / q_{t+1}
$$


As to retired entrepreneurs, since some firms may be insolvent, and the corresponding share of entrepreneurs has zero income, the retired entrepreneurs' consumption is limited toaggregate positive real profits. In order to compute them, let us recall that a firm that operates at the profit-maximizing real debt-output ratio

$$
\begin{aligned}
v^{*}{ }_{j t} & =\underline{s}^{*}{ }_{j t} n^{*}{ }_{j t} R_{t} / y^{*}(t)_{j t+1} \\
& =q^{e}{ }_{j t+1} \beta_{t} / 2
\end{aligned}
$$

is solvent if

$$
q_{t+1} \geq v^{*}{ }_{j t}
$$

i.e. if

$$
q^{e}{ }_{j t+1} \leq q_{t+1} 2 / \beta_{t} \equiv \hat{q}_{t+1}
$$

In words, a firm turns out to be solvent in $t+1$ if its expected inflation rate in $t$ was no greater that the threshold level $q_{t+1} 2 / \beta_{t}$, that we define $\hat{q}_{t+1}$. Conversely, in $t+1$ there fail all firms that had "too optimistic" inflation expectations in $t$ exceeding $\hat{q}_{t+1}$. Note the important points that i) $\hat{q}_{t+1}$ is the same for all firms, so that we can drop the index $j$, and ii) it cannot be known in advance given our assumptions. This is an important preliminary result on which we shall return later. Now we proceed with the computation of aggregate positive real profits.

Aggregate positive real profits $\Pi_{t+1}$ are the profits of all firms with $q_{j t+1}^{e} \in\left[q_{t+1}^{e \mathrm{~L}}, \hat{q}_{t+1}\right]$. From (4.1) we can write the following equalities:

$$
\begin{gathered}
q_{t+1}^{e \mathrm{~L}_{t+1}}=\omega_{t+1} u_{t}^{\mathrm{L}} \\
q_{j t+1}^{e_{j+1}}=\omega_{t+1} u_{j t} \\
\hat{q}_{t+1}=\omega_{t+1} \hat{u}_{t}
\end{gathered}
$$

Using the definition of solvency, the definition of $v^{*}{ }_{j t}$, and these equalities, we can express the aggregate positive real profits in terms of the primitives $\mathrm{u}_{j t}$ and therefore 


$$
C(t)_{j t+1}=J \int_{u_{t}^{L}}^{\hat{u}_{t}}\left(q_{t+1}-\omega_{t+1} u_{j t} \beta_{t} / 2\right)\left(u_{t}^{H}-u_{t}^{L}\right)^{-1} d u_{j t}
$$

We can now compute the equilibrium price level at $t+1$, which must satisfy

$$
C(t)_{w t+1}+C(t)_{j t+1}=W
$$

The result is a quadratic function in $q_{t+1}$ :

$$
\gamma_{0} q_{t+1}^{2}+\gamma_{1} \omega_{t+1} q_{t+1}+\gamma_{2} \omega_{t+1}^{2}=0
$$

In terms of the population's parameters $\left\{\beta_{t}, \mu_{t}, \Delta_{t}\right\}$, the coefficients of equation (4.14) result:

$$
\begin{aligned}
& \gamma_{o}=-\frac{2 \Delta_{t}+1}{\beta_{t} \Delta_{t}} \\
& \gamma_{1}=-\left(1+\mu_{t}-\Delta_{t} / 2\right) \\
& \gamma_{2}=\frac{\beta_{t}\left(\mu_{t}+\Delta_{t} / 2\right)^{2}}{4 \Delta_{t}}+1
\end{aligned}
$$

\subsection{Determination of the inflation rate}

Equation (4.14) has two roots of generic form:

$$
q^{*}{ }_{t+1}=k_{t} \omega_{t+1}
$$

where

$$
k_{t}=\frac{1}{2 \gamma_{o}}\left[-\gamma_{1} \pm \sqrt{\gamma_{1}^{2}-4 \gamma_{o} \gamma_{2}}\right]
$$

Before proceeding, note that (4.15) has the same form as the "conjectural" equation used by entrepreneurs (4.1), and it correponds to the "theoretical" model only when $k_{t}=1$. However, the "true" (or better, 
the structural) generating process is (4.15), not (4.1). Therefore, we can put forward our first proposition

(P1) The inflation generating process in the economy is self-referential, in that the relevant structural relationship is a function of the parameters characterizing the conjectures of the population about the structural relationship itself.

Since $\gamma^{2}{ }_{1}-4 \gamma_{0} \gamma_{2}>0$, equation (4.14) has two real roots, one of which is surely negative and hence non admissible. For a positive real root to exist it is necessary and sufficient that:

$$
\left(\gamma^{2}{ }_{1}-4 \gamma_{0} \gamma_{2}\right)^{1 / 2}>-\gamma_{1}
$$

and then take the root

$$
k_{t}=-\frac{1}{2 \gamma_{o}}\left[\gamma_{1}+\sqrt{\gamma_{1}^{2}-4 \gamma_{o} \gamma_{2}}\right]
$$

Since there are three free parameters, it is not possible to find a single constraint that satisfies this condition. Here we provide some combinations of parameters that may be useful in the simulation. In table 1 we take $\beta_{t}$ and $\mu_{\mathrm{t}}$ as given, and for each combination between them we indicate the range of values of $\Delta_{t}$ that fulfills the condition $k_{t}>$ 0 (the values of $\Delta_{t}$ in parentheses are implied by the chosen value of $\mu_{t}$ )

Table 1. Values of $\Delta_{t}$ consistent with $k_{t}>0$, given $\beta_{t} e \mu_{t}$

\begin{tabular}{|l|c|c|c|}
\hline & $\begin{array}{c}\mu_{\mathrm{t}}=0.5 \\
\left(\Delta_{t} \leq 1\right)\end{array}$ & $\begin{array}{c}\mu_{\mathrm{t}}=1 \\
\left(\Delta_{t} \leq 2\right)\end{array}$ & $\begin{array}{c}\mu_{\mathrm{t}}=2 \\
\left(\Delta_{t} \leq 4\right)\end{array}$ \\
\hline$\beta_{t}=0.5$ & $\Delta_{\mathrm{t}}>0$ & $\Delta_{\mathrm{t}}>0$ & $\Delta_{\mathrm{t}}>0$ \\
\hline$\beta_{t}=0.8$ & $\Delta_{\mathrm{t}}>0$ & $\Delta_{\mathrm{t}}>0$ & $\Delta_{\mathrm{t}}>0$ \\
\hline
\end{tabular}

The table shows that any heterogeneous population is consistent with a positive root of the inflation equation for the chosen values of $\beta_{t}$ and $\mu_{t}$. 
To gauge the relationship between the population' $\mathrm{s}$ parameters and the structural parameter $k_{t}$, let us first consider the average conjecture in the economy $\mu_{t}$. The relationship between $k_{t}$ and $\mu_{t}$ is the first indicator of the effect that the conjectures have on the structure of the economy. For instance, when this relationship has positive sign, conjectures tend to be self-fulfilling. Figure 2 shows that this is indeed the case in our economy, where $k_{t}$ is plotted against $\mu_{t}$ for a given $u^{\mathrm{L}}=0$ and two values of $\beta_{t}=0.5,0.8$. The figure also shows that the parameter $\beta_{t}$ exerts a further effect of positive sign on the relationship between $\mu_{t}$ and $k_{t}$.

\section{[Figure 2]}

The economic reason of these results lies in the effect that conjectures and the marginal expected bankruptcy cost have on entrepreneurs' decisions. Since conjectures are bounded from below (they cannot fall below $u^{\mathrm{L}}=0$ ), an increase in $\mu_{t}$ is the result of a greater upper bound $u^{\mathrm{H}}$, that is to say a larger tail of high-inflation forecasters. These are prone to demand more labour and pay higher wages which in turn will feed higher demand of retired workers. Likewise, an increase in $\beta_{t}$, i.e. a fall in the marginal expected cost of bankruptcy, affects all ecntrepreneurs boosting their labour demand and inducing them to pay higher wages.

As far as the other population' s parameter is concerned, i.e. the dispersion of conjectures $\Delta_{t}$, let us take as a benchmark $\mu_{t}=1$. This corresponds to a case in which the conjectures of the population are on average equal to the "theoretical value" of $k_{t}$. Figure 3 shows that $k_{t}$ is increasing in $\Delta_{t}$ and that $\beta_{t}$ is a positive shifting parameter as before. An increase in $\Delta_{t}$ for a given $\mu_{t}$ corresponds to a so-called "mean preserving spread" (MPS) in the population' s conjectures, which implies that both tails of low-inflation and high-inflation forecasters enlarge. How these two forces combine to produce, ceteris paribus, a higher inflation rate level depends on the working of the bankruptcy mechanism in the economy that will be discussed below.

[Figure 3] 


\subsection{Fixed points}

A critical issue in all self-referential models is the existence of fixed points in the map from the beliefs about a variable to the actual value of that variable. This problem is important for two reasons which relate to the notion of rational expectations (RE). The first is that if such a fixed point exists we may then check wheteher it can act as an attractor of beliefs under some law of motion of beliefs themselves. The second is that, in a self-referential system, such a fixed point is a necessary but not sufficient condition for the standard or "strong" notion of $\mathrm{RE}$ (i.e. the case whereby beliefs coincide with the "theoretical" value of the variable). Indeed, as we shall see, in our system a fixed point may exist in the map from conjectures to $k_{t}$, but the latter may not coincide with the "theoretical" value of 1 . In other words, we need two conditions for the "strong" REH to hold:

$$
\begin{aligned}
\mu_{t} & =k_{t} \\
k_{t} & =1
\end{aligned}
$$

Knowing that

$$
\mu_{t}=u^{\mathrm{L}}{ }_{t}+\Delta_{t} / 2
$$

the following table reports the values of $\Delta_{t}$ that satisfy the condition $\mu_{t}=$ $k_{t}$ for given values of $\beta_{t}$ and $u^{\mathrm{L}}{ }_{t}$

Table 3. Values of $\Delta_{t}$ that satisfy $\mu_{t}=k_{t}$, given $\beta_{t}$ e $u^{L} t$

\begin{tabular}{|l|l|l|l|}
\hline & $\mathrm{u}^{\mathrm{L}}=0$ & $\mathrm{u}_{t}=1$ & $\mathrm{u}_{t}=2$ \\
\hline$\beta_{t}=0.2$ & $\begin{array}{l}\Delta_{\mathrm{t}}=0.387 \\
k_{t}=0.193\end{array}$ & none $\left(\Delta_{\mathrm{t}}=0\right)$ & none $\left(\Delta_{\mathrm{t}}=0\right)$ \\
\hline$\beta_{t}=0.5$ & $\begin{array}{l}\Delta_{\mathrm{t}}=0.651 \\
k_{t}=0.325\end{array}$ & none $\left(\Delta_{\mathrm{t}}=0\right)$ & none $\left(\Delta_{\mathrm{t}}=0\right)$ \\
& & & \\
\hline
\end{tabular}


The noteworthy result is that fixed points $\mu_{t}=k_{t}$ exist only in a limited domain of values of the population' $s$ parameters. In that domain, however, the "strong" RE hypothesis $\left(\mu_{t}=k_{t}=1\right)$ does not hold. The conclusion is not that beliefs have no rational anchor, but that they are self-fulfilling on a "non fundamental" equilibrium on average. Take for instance the second row, first column in table 3 . It shows that a population born at time $t$ characterized by the average expectation $q_{t+1}^{e}$ $=0.325 \omega_{t+1}$, comprised between 0 and $0.651 \omega_{t+1}$, and with $\beta_{t}=0.5$ will in fact generate an inflation rate $q_{t+1}=0.325 \omega_{t+1}$, which is lower than it would be under "strong" RE, i.e. $q_{t+1}=\omega_{t+1}$. See also figure 2 , which shows how the function $k_{t}\left(\mu_{t}\right)$ intersects the locus $k_{t}=\mu_{t}$.

\subsection{Bankruptcies}

A key feature of our model is that firms may go bankrupt. This event occurs because an entrepreneur in $t$ may have an individual inflation expectation too high, that is to say his/her $q_{j t+1}^{e}$ exceeds the threshold value given by (4.11). As already remarked above, this value cannot be known in advance because it depends on what the actual inflation rate $q_{t+1}$ will be. But as we have seen, $q_{t+1}$ is in turn a function of the population' $s$ parameters, that is to say all uncertainty in the economy is "endogenous" since it arises from the conjectures of entrepreneurs $u_{j t}$ about the inflation generating process, and the selfreferentiality effect. In other words, we might say that whether a firm fails or not in this economy only depends on relative expected prices.

In order to compute the share of firms that fail in each period, let us recall that the insolvency condition is

$$
q_{j t+1}^{e}>q_{t+1} 2 / \beta
$$

or, in terms of $u_{j t}$,

$$
\begin{gathered}
u_{j t} \omega_{t+1}>k_{t} \omega_{t+1} 2 / \beta \\
u_{j t}>k_{t} 2 / \beta \equiv \hat{u}_{t}
\end{gathered}
$$


Therefore, in the first place, a necessary condition on the population' s parameters should hold for failures to occur, i.e.:

$$
u_{t}^{\mathrm{H}}>k_{t} 2 / \beta
$$

or

$$
\Delta_{t}>k_{t} 4 / \beta-2 \mu_{t}
$$

Table 4 reports the values of $\Delta_{t}$ consistent with non-zero failures in the economy for given values of $\mu_{t}$ and $\beta_{t}$.

Table 4. Values of $\Delta_{\mathbf{t}}$ consistent with non-zero failures, given $\mu_{\mathbf{t}}$ and $\beta_{t}$

\begin{tabular}{|l|c|c|c|}
\hline & $\begin{array}{c}\mu_{t}=0.5 \\
\left(\Delta_{t} \leq 1\right)\end{array}$ & $\begin{array}{c}\mu_{t}=1 \\
\left(\Delta_{t} \leq 2\right)\end{array}$ & $\begin{array}{c}\mu_{t}=2 \\
\left(\Delta_{t} \leq 4\right)\end{array}$ \\
\hline$\beta_{t}=0.5$ & none $^{*}$ & $\Delta_{t}>0.67$ & $\Delta_{t}>0$ \\
\hline$\beta_{t}=0.8$ & none $^{+}$ & $\Delta_{t}>0$ & $\Delta_{t}>0$ \\
\hline$\Delta^{*}{ }_{t}>3.0$ & \\
$\Delta+$ &
\end{tabular}

We observe that for failures to occur the population should display a critical combination of parameters. Intuitively, failures occur as a result of a combination of large dispersion of conjuctures $\Delta_{t}$, and/or high average of conjectures $\mu_{t}$, and/or low marginal expected bankruptcy cost (high $\beta_{t}$ ). These three factors are consistent with the bankruptcy mechanism in our economy: each of them, directly or indirectly, implies a larger tail of firms on the high-inflation side of the population' $s$ forecasts.

This intuition is confirmed by the computation of the share of bankruptcies in the population, which is equal to: 


$$
\begin{aligned}
\phi_{t+1} & =1-F\left(\hat{u}_{t}\right) \\
& =1-\left(\hat{u}_{t}-u^{\mathrm{L}}{ }_{t}\right) / \Delta_{t} \\
& =1 / 2+\left(\mu_{t}-k_{t} 2 / \beta_{t}\right) / \Delta_{t}
\end{aligned}
$$

i.e. a non-linear function of the population' $\mathrm{s}$ parameters. Figure 4 portrays the function (4.17) for $\mu_{t}=1$ and $\beta_{t}=0.5,0.8$ (see the third column in table 4). When $\beta_{t}=0.5, \phi_{t+1}$ increases with $\Delta_{t}$. Yet $\beta_{t}$ acts as a positive shifting parameter. As $\beta_{t}$ changes from 0.5 to 0.8 , bankruptcies occur even at low levels of $\Delta_{t}$ and are consistently larger than in the previous case, though $\Delta_{t}$ now has a negligible effect.

\section{[Figure 4]}

In the tables below we provide some numerical expamles of comparative statics of different populations, and hence of different resulting values of $k_{t}, \hat{u}_{t}$ and $\phi_{t+1}$

A) $\mu_{\mathrm{t}}=1, \Delta_{\mathrm{t}}=1\left(\mathrm{u}_{\mathrm{t}}=0.5, \mathrm{u}_{\mathrm{t}}^{\mathrm{H}}=1.5\right)$

\begin{tabular}{|l|l|l|l|}
\hline & $k_{t}$ & $\hat{u}_{t}$ & $\phi_{t+1}$ \\
\hline$\beta_{t}=0.5$ & 0.354 & 1.416 & $8.4 \%$ \\
\hline$\beta_{t}=0.8$ & 0.453 & 1.13 & $36.7 \%$ \\
\hline
\end{tabular}

B) $\mu_{\mathrm{t}}=1, \Delta_{\mathrm{t}}=1.4\left(\mathrm{u}_{\mathrm{t}}=0.3, \mathrm{u}_{\mathrm{t}}^{\mathrm{H}}=1.7\right)$

\begin{tabular}{|l|l|l|l|}
\hline & $k_{t}$ & $\hat{u}_{t}$ & $\phi_{t+1}$ \\
\hline$\beta_{t}=0.5$ & 0.376 & 1.505 & $13.9 \%$ \\
\hline$\beta_{t}=0.8$ & 0.482 & 1.205 & $35.4 \%$ \\
\hline
\end{tabular}


Taking the two tables separately one can single out the effect of $\beta_{t}$ which, as explained above, measures the effect of the marginal expected bankruptcy cost. Low expected bankruptcy cost (high $\beta_{t}$ ) boosts labour demand: wages rise, and so do demand and the future price level (see effect on $k_{t}$ ). On the other hand, the entrepreneurs' willingness to pay a larger wage bill implies that borrowing increases; this is another way, a way that looks at the increase in "inside" money, to explain the upward pressure on the price level. On this front, two opposite forces are at work. First, more borrowing means more bankruptcy risk on each firm. Second, a higher inflation rate is beneficial for it raises $\hat{u}_{t}$ and makes it shrink the tail of firms bound to insolvency. The negative effect on $\hat{u}_{t}$ of a greater $\beta_{t}$ in both tables indicates that the first force prevails on the second, so that the share of bankruptcies eventually grows (see the effect on $\phi_{t+1}$ ). These examples point out a pattern where "inside" inflationary conditions are associated with greater bankruptcy risk and actual bankruptcies.

If one compares the two tables, one can gauge the consequences of a MPS in the population' s conjectures $u_{j t}$. For $\beta_{t}=0.5$, the MPS has an unambiguous "inside" inflationary effect combined with larger bankruptcies for the reasons explained above. For $\beta_{t}=0.8$ the inflationary effect of the MPS is instead accompanied with fewer bankruptcies, which means that in this case the beneficial effect of "inside" inflation prevails.

Finally, it may also be worth stressing that the bankruptcy rate is independent of the (anticipated) rate of outside money growth. Racalling that the marginal expected bankruptcy cost (the $\beta$-effect) reduces the real wage bill relative to the certainty case and that actual bankruptcies are a consequence of overproduction by some firms, one might conclude that money transfers to workers should sustain aggregate demand and reduce bankruptcies. This is not the case, however, because the bankruptcy probability eventually depends on the relative expected inflation of an entrepreneur: as long as money creation is anticipated, it raises the expected inflation rate of all entrepreneurs 
uniformly thus leaving their relative positions and bankruptcy probability unchanged.

\section{Tareddraics}

The previous sections set out the properties of an economy characterized as a self-referential system fed by entrepreneurs' conjectures about the inflation-generating process, and a failure mechanism entirely determined by the self-referentiality effect of individual conjectures and their heterogeneity. The results presented above hold for a single two-period sequence taken in isolation and hence are essentially comparative-static in nature.

The next natural step in the presence of failures is to move towards population' s dynamics in relation to two forces 1)election, due to the exit from market of bankrupt firms, 2) learning, due to the incentive of incumbent entrepreneurs to avoid failure and/or to improve their performance.

Each of the two evolutionary mechanisms requires non-trivial assumptions and creates non-trivial analytical problems.

Selection. The first conceivable mechanism is that all insolvent firms are eliminated from the population and replaced with new entrants. Note that it may be necessary to distinguish between the entrepreneur, who exits from activity after 1 period by assumption, and the firm, which may be thought of as an institution that survives generation after generation. Newborn entrepreneurs taking control of pre-existing firms may also entrust the firm' s memory of past conjectures. $\mathrm{Bu}$ contrast, bankruptcy means that the institution is destroyed with all its memory. Accordingly, newborn entrepreneurs undertaking new firms can be modelled as endowed with randomly generated conjectures and zero memory. 
Learning. The environment in which incumbent firms operate in our model has two peculiar features that distinguish it form more usual learning models.

First, the problem of the incentive to learn arises. This problem is substantially unaddressed in the literature. Note that each period ends up with three classes of firms: a) insolvent firms, b) solvent firms with profit lower than expected, c) solvent firms with profit greater than expected. The class of firms a) has to be selected away as explained above. What about the other two classes of firms? Suppose a survived firm' s memory at the end oft+1 contains (at least) the last conjecture $u_{j t}$, and this memory is handed down the incoming entrepreneur. The rather natural question is: why the incoming entrepreneur should engage in learning, that is to say why he/she should modify the inherited successful conjecture? The argument that the inherited conjecture was nonetheless incorrect is nonsensical, for the reason that the probability of an exact forecast in our continuous setup is zero. The argument that the firms in the class b) have an incentive to improve is plausible, but obviously cannot be extended to class c).

Second, self-referentiality has a crucial implication for learning. Classical learning models assume a stable structure of the object of learning - the inflation generating process in our case. By contrast, selfreferentiality entails that the structure of the object of learning coevolves with the learning process. This property is quite clear in our model. The structure of the inflation generating process consists of the parameter $k_{t}$. This parameter is a function of the population' $\mathrm{s}$ parameters $\left\{\delta_{t}, \mu_{t}, \Delta_{t}\right\}$. The selection mechanism, the substitution of bankrupt firms with new ones, implies that $t+1$ starts with a modified distribution of conjectures $u_{j t+1}$, and hence with modified parameters $\left\{\delta_{t+1}, \mu_{t+1}, \Delta_{t+1}\right\}$, with respect to the previous ones. Hence selection by itself implies that $k_{t}$ changes over time. As a consequence,

- successful conjectures in one period may no longer be such in the subsequent period 
- the process driving the dynamics of $k_{t}$ is fully determined by the population' $\mathrm{s}$ dynamics and, under our assumptions, is totally hidden from individual agents' view

- large population innovations exert a negative externality on incumbents (whether they are engaged in learning or not), whereas conservative incumbents exert a positive externality on all incumbents and learners in particular.

At the present stage of development of our research, we limit ourselves to the analysis of the implications of self-referentiality under the population dynamics generated by exits and entries, whereas we substantially rule out learning by assuming that all entrepreneurs in solvent firms do not revise the previous generation' $\mathrm{s}$ conjecture. To begin with, we also leave the parameters $\delta_{t+1}, \Delta_{t+1}$ unchanged over time.

\subsection{Population's dynamics}

Given the distribution of insolvent and solvent firms at the end of any period $t$ as explained in section 4 , the former are driven out of the market and replaced by new ones which leave the measure of the class of entrepreneurs $J$ unchanged.

Consequently, in any new period $t+1$ there exist two groups of newborn entrepreneurs: those who run a pre-existing firm and those who run a new one. Recall that the sole individual characteristic that distinguishes entrepreneurs and firms is the conjecture $u_{j t+1}$ whereby each of them transforms the announced one-period growth rate of money $\omega_{t+2}$ into a one-period inflation forecast $p^{e}{ }_{j t+2}=u_{j t+1} \omega_{t+2}$. We assume that the entrepreneurs running pre-existing firms hold the previous period' $\mathrm{s}$ (successful) conjecture in the firm' $\mathrm{s}$ "memory" $u_{j t}$, whereas the entrepreneurs running new firms form new individual conjectures following the same statistical law as their predecessors, that is to say a uniform distribution with density $f\left(u_{j t+1}\right)$ and $u_{j t+1} \in$ $\left[u_{t}^{\mathrm{L}}, u^{\mathrm{H}}{ }_{t}\right.$. Also, all newborn entrepreneurs hold their individual forecasts with the same tolerance parameter $\delta_{t}$ as in the previous 
generation, i.e. $p^{e \mathrm{~L}}{ }_{j t+2}=p^{e}{ }_{j t+2}-\delta_{t}, p^{e \mathrm{H}}{ }_{j t+2}=p^{e}{ }_{j t+2}+\delta_{t}$. Being constant over time, the parameters $\Delta=u^{\mathrm{H}}-u^{\mathrm{L}}$, and $\delta$ will be expressed without time subscript.

\subsection{The dynamics of the distribution of conjectures}

The population dynamics described above brings as a major implication a period by period modification of the distribution of conjectures (and hence inflation forecasts) in the population of firms. We first give an intuitive graphical rendition of this process.

[Figure 5]

The first panel in figure 5 portrays the initial uniform distribution of conjectures at beginning of period $t$ with the parameters given in the example $\mathrm{A}$ (first row) above, i.e. $\mathrm{u}^{\mathrm{L}}=0.5, \mathrm{u}^{\mathrm{H}}=1.5, \delta=1(\beta=$ $0.5)$. The second panel represents the consequence of the firms' exit mechanism given that the insolvency threshold results $\hat{u}_{t}=1.416$ (with $8.4 \%$ of firms going bankrupt). The third panel exemplifies the consequence of the new firms' entry mechanism: $8.4 \%$ of the previous distribution above $\hat{u}_{t}$ is removed and "spread" over the whole support with the effect that the tail of conjectures below $\hat{u}_{t}$ is larger, while that above $\hat{u}_{t}$ is smaller, than before. Therefore, though a mixture of two identical uniform distributions, the resulting distribution is no longer uniform. Owing to the assumption that the previous period' s successful conjectures are transmitted to the new entrepreneurs running preexisting firms while are also randomly represented among the new entrepreneurs of new firms, these successful conjectures gain weight in the population.

More formally, let us start form the original set of random conjectures $U_{t}$ uniformly distributed with density function $f\left(u_{j t}\right), u_{j t} \in$ $\left[u^{\mathrm{L}}, u^{\mathrm{H}}\right]$, in period $t$. The consequence of the exit mechanism is equivalent to truncating the support of $U_{t}$ at $\hat{u}_{t}$ so that the conjectures of solvent firms, $U^{s}{ }_{t} \in U_{t}$, are realizations from the uniform random 
variable $U^{s}{ }_{t} \sim U\left(u^{\mathrm{L}}{ }_{t}, \hat{u}_{t}\right)$. The consequence of the entry mechanism in period $t+1$ is that the conjectures are realizations from the random variables $U_{t+1}$ and $U^{s}{ }_{t}$ according to the following law

$$
\left\{\begin{array}{l}
\text { from } U_{t}^{s} \sim U\left(u^{\mathrm{L}}, \hat{u}_{t}\right) \quad \text { with probability } q_{t} \\
\text { from } U_{t+1} \sim U\left(u^{\mathrm{L}}, u^{\mathrm{H}}\right) \quad \text { with probability } 1-q_{t}
\end{array}\right.
$$

where

$$
q_{t}=\frac{\hat{u}_{t}-u^{\mathrm{L}}}{u^{\mathrm{H}}-u^{\mathrm{L}}}
$$

Consequently, the density function of conjectures in period $t+1$, $f\left(u_{j t+1}\right)$, can be written as

$$
f\left(u_{j t+1}\right)=q_{t} f_{1}\left(u_{j t+1}\right) I_{u_{, u_{t}}}\left(u_{j t+1}\right)+\left(1-q_{t}\right) f_{2}\left(u_{j t+1}\right) I_{u^{\mathrm{L}}, u^{\mathrm{H}}}\left(u_{j t+1}\right)
$$

where $f_{1}$ and $f_{2}$ are two density functions defined as follows:

$$
f_{1}\left(u_{j t+1}\right)=\left\{\begin{array}{cc}
\left(\hat{u}_{t}-u^{\mathrm{L}}\right)^{-1} & u_{j t+1} \in\left[u^{\mathrm{L}}, \hat{u}_{t}\right] \\
0 & \text { elsewhere }
\end{array}\right.
$$

$$
f_{2}\left(u_{j t+1}\right)=\left\{\begin{array}{cl}
\left(u^{\mathrm{H}}-u^{\mathrm{L}}\right)^{-1} & u_{j t+1} \in\left[u^{\mathrm{L}}, u^{\mathrm{H}}\right] \\
0 & \text { elsewhere }
\end{array}\right.
$$

and $I_{u} \mathrm{~L}_{\hat{u}_{t}}\left(u_{j t+1}\right)$ and $I_{u} \mathrm{~L}_{, u} \mathrm{H}\left(u_{j t+1}\right)$ are two indicator functions defined as follows 


$$
\begin{gathered}
I_{u} \mathrm{~L}_{, \hat{u}_{t}}\left(u_{j t+1}\right)= \begin{cases}1 & u_{j t+1} \in\left[u^{\mathrm{L}}, \hat{u}_{t}\right] \\
0 & u_{j t+1} \notin\left[u^{\mathrm{L}}, \hat{u}_{t}\right]\end{cases} \\
I_{u} \mathrm{~L}_{, u} \mathrm{H} \\
\left(u_{j t+1}\right)= \begin{cases}1 & u_{j t+1} \in\left[u^{\mathrm{L}}, u^{\mathrm{H}}\right] \\
0 & u_{j t+1} \notin\left[u^{\mathrm{L}}, u^{\mathrm{H}}\right]\end{cases}
\end{gathered}
$$

We are now in a position to compute the expected value of the conjectures in period $t+1, \mu_{t+1}$. Since the other two population' $\mathrm{s}$ parameters, $\Delta$ and $\delta$, are constant by assumption, $\mu_{t+1}$ represents the evolution of the population owing to the exit and entry mechanism. It follows straightforwardly from (5.3) that

$$
\mu_{t+1}=q_{t} \mu_{1}+\left(1-q_{t}\right) \mu_{2}
$$

where

$$
\begin{aligned}
& \mu_{1}=\left(u^{\mathrm{L}}+\hat{u}_{t}\right) / 2 \\
& \mu_{2}=\left(u^{\mathrm{L}}+u^{\mathrm{H}}\right) / 2
\end{aligned}
$$

Let us now go back to figure 5 of which we can give a rigorous quantification. The distribution of conjectures represented in the third panel is the result of a mixture of the uniform distribution $U(0.5,1.416)$ with probability 0.916 , and of the uniform distribution $U(0.5,1.5)$ with probability 0.084 . Therefore, the density function of the conjectures of period $t+1$ is

$$
f\left(u_{j t+1}\right)=0.916 \times f_{1}\left(u_{j t+1}\right) I_{u^{\mathrm{L}} \hat{u}_{t}}\left(u_{j t+1}\right)+0.084 \times f_{2}\left(u_{j t+1}\right) I_{u^{\mathrm{L}}, u} \mathrm{H}\left(u_{j t+1}\right)
$$

where 


$$
\begin{aligned}
& f_{1}\left(u_{j t+1}\right)=\left\{\begin{array}{cc}
\frac{1}{0.916} & u_{j t+1} \in[0.5,1.416] \\
0 & \text { elsewhere }
\end{array}\right. \\
& f_{2}\left(u_{j t+1}\right)=\left\{\begin{array}{cc}
1 & u_{j t+1} \in[0.5,1.5] \\
0 & \text { elsewhere }
\end{array}\right.
\end{aligned}
$$

And, by applying (5.6), the expected value of conjectures results to be:

$$
\mu_{t+1}=0.916 \times 0.958+0.084=0.961
$$

Unsurprisingly, the average conjecture in period $t+1$ is lower than in period $t\left(\mu_{t}=1\right)$. In fact, the lower tail of the previous period' $\mathrm{s}$ conjectures has gained weight in the new period' s population of firms as a consequence of the exit and entry mechanism. We have argued above that in our economy the entrepreneurs who are bound to fail are those whose conjecture lies above a threshold value which depends, inter alia, on the average conjecture in the population. Should we expect a fall in the share of bankruptcies, and can we conclude that the population and conjectures dynamics that we have so far examined will, by expelling over-optimistic conjectures, determine a period by period shrink of the bankruptcy probability in the economy ending up with zero bankruptcies? These are our matters of investigation on the long-run properties of our economy.

\subsection{Asymptotic properties of the economy}

In this section we investigate the behavior of $\hat{u}_{t}$ in the long run, that is, more formally, we analyze the asymptotic properties of the distribution of conjectures.

First, we look at the evolution of the parameters of the distribution of conjectures over time. At time 0 the expected value is given by $\mu_{0}=\left(u^{L}+u^{H}\right) / 2$. From this expected value we get $k_{0}=g_{1}\left(\mu_{0}\right)$ and $\hat{u}_{0}=g_{2}\left(k_{0}\right)$. The functions $g_{1}$ and $g_{2}$ are given by 


$$
\begin{aligned}
& k_{t}=g_{1}\left(\mu_{t}\right)=\frac{1}{2} \gamma_{0}{ }^{(t)}\left(-\gamma_{1}{ }^{(t)}-\sqrt{\left(\gamma_{1}{ }^{(t)}\right)^{2}-4 \gamma_{0}{ }^{(t)} \gamma_{2}{ }^{(t)}}\right) \\
& \hat{u}_{t}=g_{2}\left(k_{t}\right)=\frac{2 k_{t}}{\beta} .
\end{aligned}
$$

where $\gamma_{0}{ }^{(t)}, \gamma_{1}{ }^{(t)}$ and $\gamma_{2}{ }^{(t)}$ are given in section 4.4. As we will see in a moment, it is essential to check whether the functions $g_{1}$ and $g_{2}$ are non-decreasing. This is obvious for $g_{2}$; as for $g_{1}$, we proved, using the Symbolic Math Toolbox of MATLAB, that it is increasing for any value of $\mu \in\left[u^{L}, u^{H}\right]$.

Entrepreneurs whose expected value of conjectures is larger than $\hat{u}_{0}=g_{2}\left[g_{1}\left(\mu_{0}\right)\right]$ go bankrupt and are excluded, so that the remaining firms are distributed uniformly between $u^{L}$ and $\hat{u}_{0}$. Then a new sample is drawn from a $U\left(u^{L}, u^{H}\right)$ distribution.

The sampling scheme at time $t=1$ is therefore as follows: with probability $q_{1}=\left(\hat{u}_{0}-u^{L}\right) /\left(u^{H}-u^{L}\right)$ we draw an observation from $U\left(u^{L}, \hat{u}_{0}\right)$, with probability $\left(1-q_{1}\right)$ we draw an observation from $U\left(u^{L}, u^{H}\right)$. Formally, this means we sample from a mixture of these two distributions, having density

From (6.8) we get new values

$$
\begin{aligned}
& f^{(1)}(x)=q_{1} \frac{1}{\hat{u}_{0}-u^{L}} I_{u^{L}, \hat{u}_{0}}(x)+\left(1-q_{1}\right) \frac{1}{u^{H}-u^{L}} I_{u^{L}, u^{H}}(x) . \\
& \begin{aligned}
\mu_{1}=q_{1} & \frac{u^{L}+\hat{u}_{0}}{2}+\left(1-q_{1}\right) \frac{u^{L}+u^{H}}{2}, \\
k_{1} & =g_{1}\left(\mu_{1}\right), \\
\hat{u}_{1} & =g_{2}\left(k_{1}\right),
\end{aligned}
\end{aligned}
$$


Notice that

$$
\begin{gathered}
\mu_{1}=q_{1} \frac{u^{L}+\hat{u}_{0}}{2}+\left(1-q_{1}\right) \frac{u^{L}+u^{H}}{2} \leq \\
q_{1} \frac{u^{L}+u^{H}}{2}+\left(1-q_{1}\right) \frac{u^{L}+u^{H}}{2}= \\
=\frac{u^{L}+u^{H}}{2}=\mu_{0} .
\end{gathered}
$$

Now, as the functions $g_{1}$ and $g_{2}$ are increasing, this implies $\hat{u}_{1} \leq \hat{u}_{0}$. Firms whose expected inflation rate is larger than $\hat{u}_{1}$ go bankrupt and are excluded so that at time 2 we sample from a mixture:

$$
f^{(2)}(x)=q_{2} \frac{1}{\hat{u}_{1}-u^{L}} I_{u^{L}, \hat{u}_{1}}(x)+\left(1-q_{2}\right) \frac{1}{u^{H}-u^{L}} I_{u^{L}, u^{H}}(x),
$$

where $q_{2}=\left(\hat{u}_{1}-u^{L}\right) /\left(u^{H}-u^{L}\right)$.

If the sequence $\left\{\hat{u}_{t}\right\}_{t \in N}$ is non-increasing, it is not difficult to see that at time $t$ we sample from a mixture

$$
f^{(t)}(x)=q_{t} \frac{1}{\hat{u}_{t-1}-u^{L}} I_{u^{L}, \hat{u}_{1-1}}(x)+\left(1-q_{t}\right) \frac{1}{u^{H}-u^{L}} I_{u^{L}, u^{H}}(x) .
$$

where $q_{t}=\left(\hat{u}_{t-1}-u^{L}\right) /\left(u^{H}-u^{L}\right)$

Thus the first thing we have to prove is that the sequence $\left\{\hat{u}_{t}\right\}_{t \in N}$ is non-increasing, because in this case the sampling scheme is established for any $t \in N$. After this, we will have to examine whether the sequence converges. 
To begin, notice that the functions $g_{1}$ and $g_{2}$ used for computing $k_{t}=g_{1}\left(\mu_{t}\right)$ and $\hat{u}_{t}=g_{2}\left(k_{t}\right)$ are known, so that we can put the problem in the functional form $\hat{u}_{t}=l\left(\hat{u}_{t-1}\right)$. With this notation we have the following result: the sequence $\left\{\hat{u}_{t}\right\}_{t \in N}$ is non-increasing if and only if $l^{\prime}(x)$ is non-negative for any $x \in\left[\hat{u}_{t}, u^{H}\right\rfloor$.

This statement can be proved by mathematical induction: we have already shown that $\hat{u}_{1} \leq \hat{u}_{0}$. Suppose now that $\hat{u}_{t} \leq \hat{u}_{t-1}$. Then, under the hypothesis that $l^{\prime}(x) \geq 0 \quad \forall x \geq \hat{u}_{t}$, we have $l\left(\hat{u}_{t}\right)-l\left(\hat{u}_{t-1}\right)=\hat{u}_{t+1}-\hat{u}_{t} \leq 0$.

To prove that the sequence converges, we use the fixed point theorem [see, for example, Burden and Faires (1993), theorem 2.3]: given the function $g \in C[a, b]$, if $g^{\prime}(x) \leq K<1 \forall x \in[a, b]$, the sequence $p_{t}=g\left(p_{t-1}\right)_{t \in N}$ converges to the unique fixed point in $[a, b]$. When applied to our setup, the theorem says that, for the sequence $\left\{\hat{u}_{t}\right\}_{t \in N}$ to converge, $l^{\prime}(x)$ must be smaller than one for any $x \in\left[u^{L}, u^{H}\right\rfloor$.

The intersection of these two results implies that we need $l^{\prime}(x)$ to be non-negative for any $x \in\left[\hat{u}_{t}, u^{H}\right\rfloor$ and smaller than one for any $x \in\left\lfloor u^{L}, u^{H}\right\rfloor$. The function $l(x)$ is quite complicated and we used again the Symbolic Math Toolbox of MATLAB to differentiate it. The first derivative $l^{\prime}(x)$ is plotted in figures $6 \mathrm{a}$ to $6 \mathrm{~d}$ for all the examples considered, i.e. $\left[u^{L}, u^{H}\right]=[0.5,1.5],\left[u^{L}, u^{H}\right]=[0.3,1.7]$, with $\beta=0.5$ and $\beta=0.8$. We see that the absolute value of the first derivative is smaller than one for all values of interest. In addition, $l^{\prime}(x)$ is positive for "large enough" values of $x$ : in the examples considered, "large enough" means larger than 1 . There is no a priori guarantee that $\hat{u}_{t} \geq 1 \forall t$ : in general, it will be necessary to check it at each iteration of the algorithm. In the examples presented this is always true. So the general strategy, given $\beta, u^{L}$ and $u^{H}$, consists in: (i) checking for which values of $x$ it holds 
that $0 \leq l^{\prime}(x)<1$; (ii) running the process until the difference $\hat{u}_{t-1}-\hat{u}_{t}$ is smaller than a prespecified tolerance level, checking at each iteration that $\hat{u}_{t}$ is such that $l^{\prime}(x) \geq 0, \forall x \geq \hat{u}_{t}$.

In the table below we report the results obtained in the examples considered; $u^{*}$ is the convergence value (in parntheses the number of iterations)

A) $\mathrm{u}^{\mathrm{L}}=0.5, \mathrm{u}^{\mathrm{H}}=1.5, \mu_{0}=1$

\begin{tabular}{|l|l|l|l|l|l|l|l|}
\hline & $k_{0}$ & $\hat{u}_{0}$ & $\phi_{1}$ & $\hat{u}^{*}$ & $\phi^{*}$ & $\mu^{*}$ & $k^{*}$ \\
\hline$\delta=1$ & 0.354 & 1.416 & $8.4 \%$ & $\begin{array}{l}1.390 \\
(20)\end{array}$ & $1.2 \%$ & 0.951 & 0.347 \\
\hline$\delta=4$ & 0.453 & 1.13 & $36.7 \%$ & $\begin{array}{l}1.077 \\
(12)\end{array}$ & $17.8 \%$ & 0.878 & 0.431 \\
\hline
\end{tabular}

B) $\mathrm{u}^{\mathrm{L}}=0.3, \mathrm{u}^{\mathrm{H}}=1.7, \mu_{0}=1$

\begin{tabular}{|l|l|l|l|l|l|l|l|}
\hline & $k_{0}$ & $\hat{u}_{0}$ & $\phi_{1}$ & $\hat{u}^{*}$ & $\phi^{*}$ & $\mu^{*}$ & $k^{*}$ \\
\hline$\delta=1$ & 0.376 & 1.505 & $13.9 \%$ & $\begin{array}{l}1.464 \\
(18)\end{array}$ & $2.8 \%$ & 0.902 & 0.366 \\
\hline$\delta=4$ & 0.482 & 1.205 & $35.4 \%$ & $\begin{array}{l}1.136 \\
(12)\end{array}$ & $16.2 \%$ & 0.832 & 0.454 \\
\hline
\end{tabular}

Notice that the sequence always converges to a value $u^{*}$ inside the interval $\left\lfloor u^{L}, u^{H}\right\rfloor$ : this means that the proportion of firms that go bankrupt is constant in the long run, and does not collapse to 0 or 1 . 


\section{Coutrias}

We have studied a model of a macro-economy in sequential time where the population of firms at each point in time is characterized by a uniform distribution of individual unobservable beliefs about the mechanism relating an observable market signal (the rate of increase of outside money) and the future inflation rate. As a consequence of heterogeneous beliefs, a certain share of the population of firms can go bankrupt and is driven out the market in each time period. The bankruptcy mechanism is such that the probability for a firm to fail depends on the parameters of the population' s beliefs and its own expected inflation relative to average. We have shown that within consistent ranges of parameters, non-zero bankruptcies obtain. The rate of bankruptcies in a given period results to be related to economically palusible effects of the parameters of the population beliefs, but not to the rate of money growth by itself (no money illusion)

Though markets are in equilibrium for incumbent firms' and workers' exchanges, bankruptcies alter equilibrium properties substantially. The system is also self-referential in that the actual inflation rate in each period turns out to be a function of the parameters of the population' s beliefs. Given this property, and the share of bankruptcies, the observed relationship between the growth rate of money and the inflation rate is no longer equal the "fundamental" or "theoretical" one. In fact, in the same ranges of parameters that yield non-zero bankruptcies, we have explored the existence of fixed points in the map that projects the averege expected inflation onto the actual one, i.e. "cross-sectional" rational expectations, and we have found that where such fixed points exist they do not coincide with the theoretical value of the inflation rate. On the one hand, this result may be added to the class of "self-fulfilling (average) prophecies", on the other, thinking of the self-fulfilled average expected inflation as an "anomaly" with respect to the inflation rate that would prevail under homogenous perfect foresight and no bankruptcies is misleading because heterogeneous beliefs and non-zero bankruptcies are part of the structure of the economy. The implication is rather that, normatively, 
the content of the rational expectations hypotesis should be extended to include the bankruptcy-generating mechanism and the way it modifies the structural relationship between the growth rate of money and the inflation rate, which seems however contradictory with the existence itself of bankruptcies.

Finally we have extended our analyis to the turnover of firms along the sequence of periods. We have started form the simplest case: bankrupt firms are "erased" (no information left to posterity) and replaced by "blank" newcomers with beliefs randomly extracetd from the existing distribution. Incumbent successful firms do not change their beliefs nor do they engage in learning. This turnover mechanism generates a dynamics of the distribution of beliefs: changes in the distribution' $\mathrm{s}$ parameters produce changes in the inflation rate and in the bankruptcy rate period after period (successful firms in one period may no longer be such in the next). Though successful firms are predominant in each period and the bankruptcy rate tends to shrink, we have found by numerical methods that the probability of bankruptcy converges towards a non-degenerate limit value. In other words, in the long run the economy displays a "structural" or "natural" rate of bankruptcy such that all the previous properties described above hold.

Figure 1

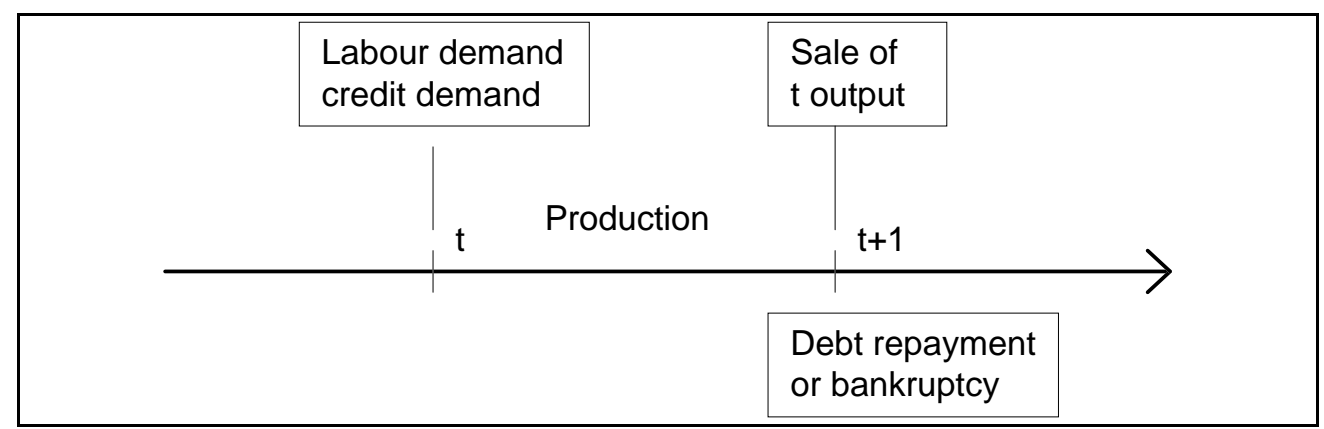


Figure $2\left(\omega^{L}=0\right)$

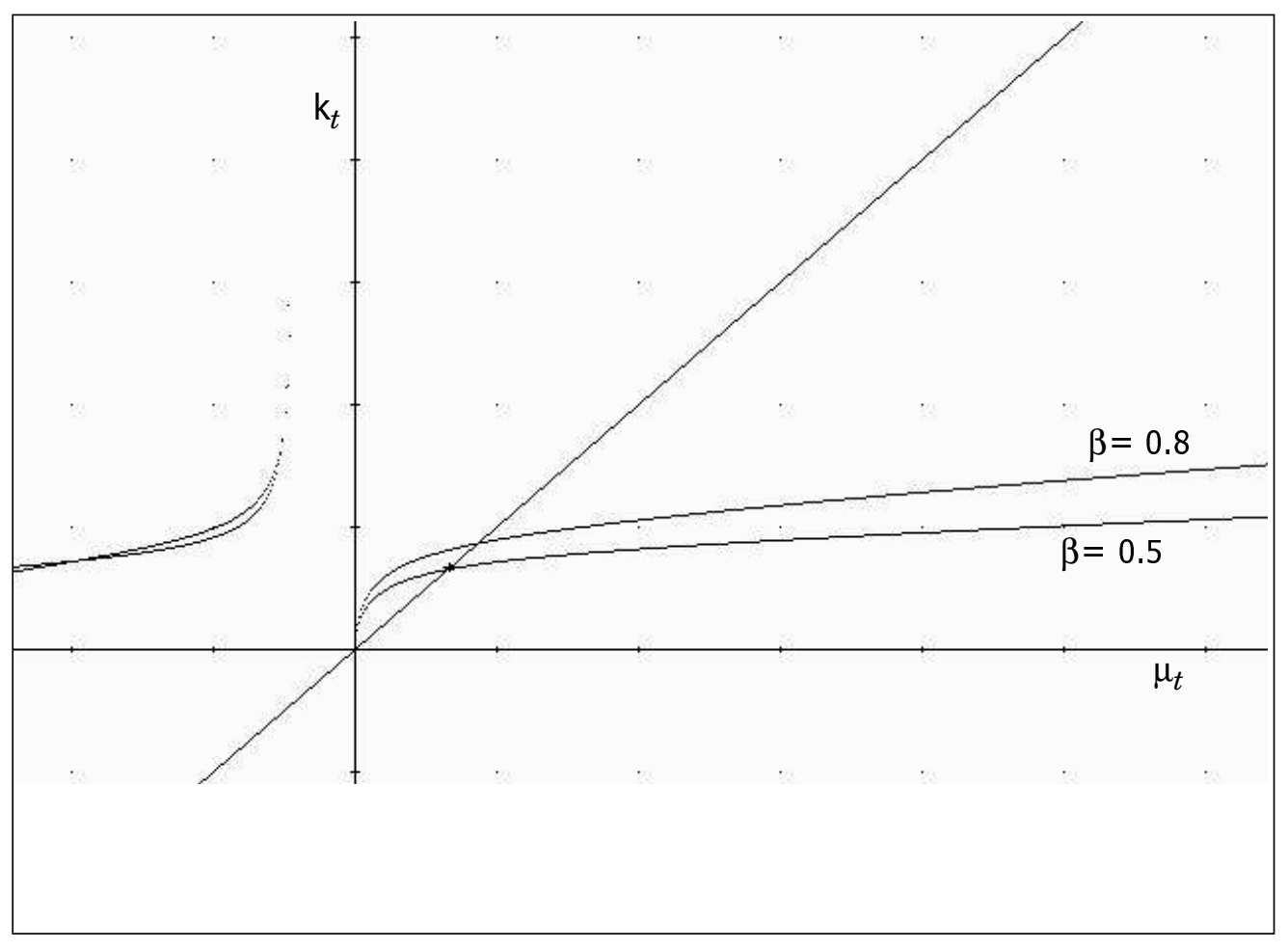


Figure $3\left(\mu_{t}=1\right)$

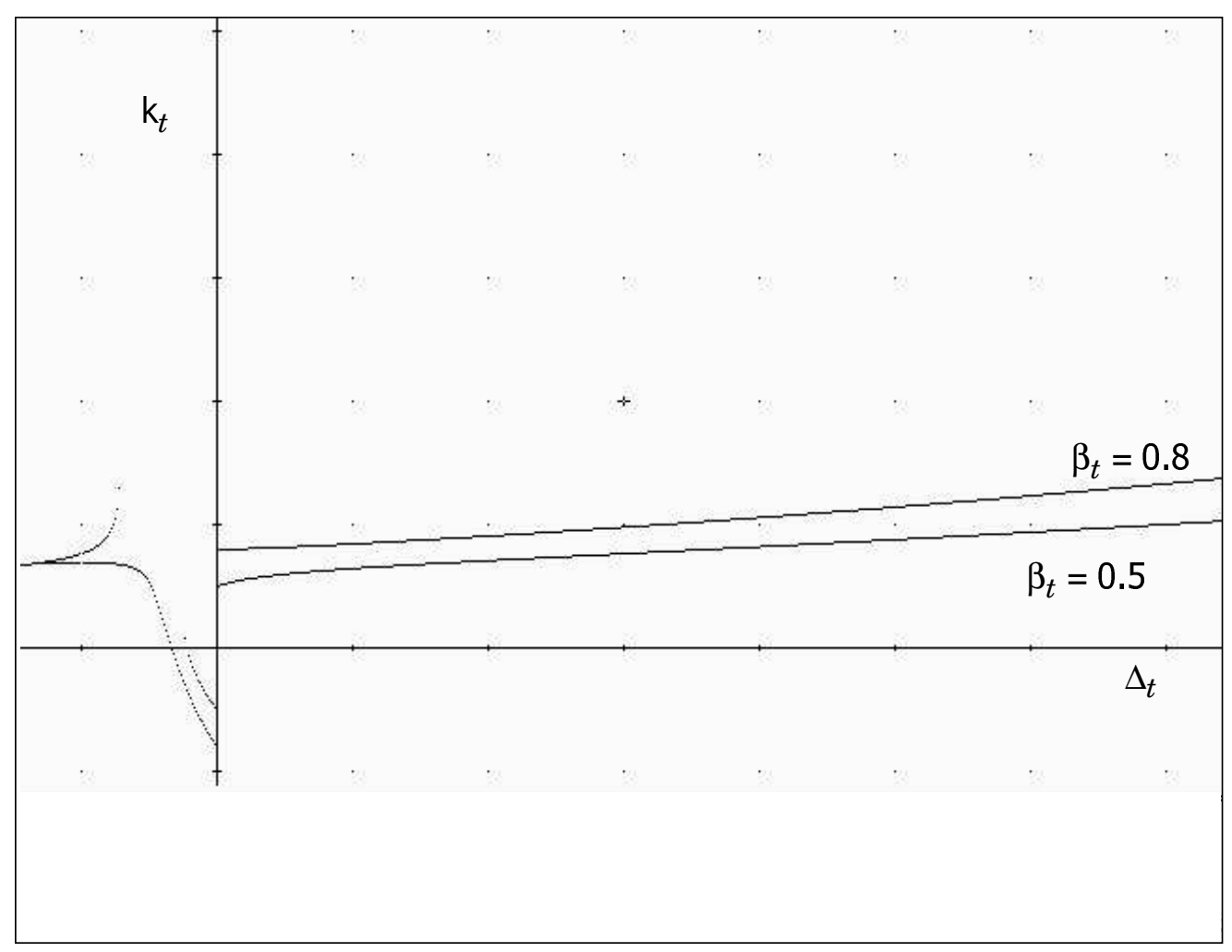


Figure $4\left(\mu_{t}=1\right)$

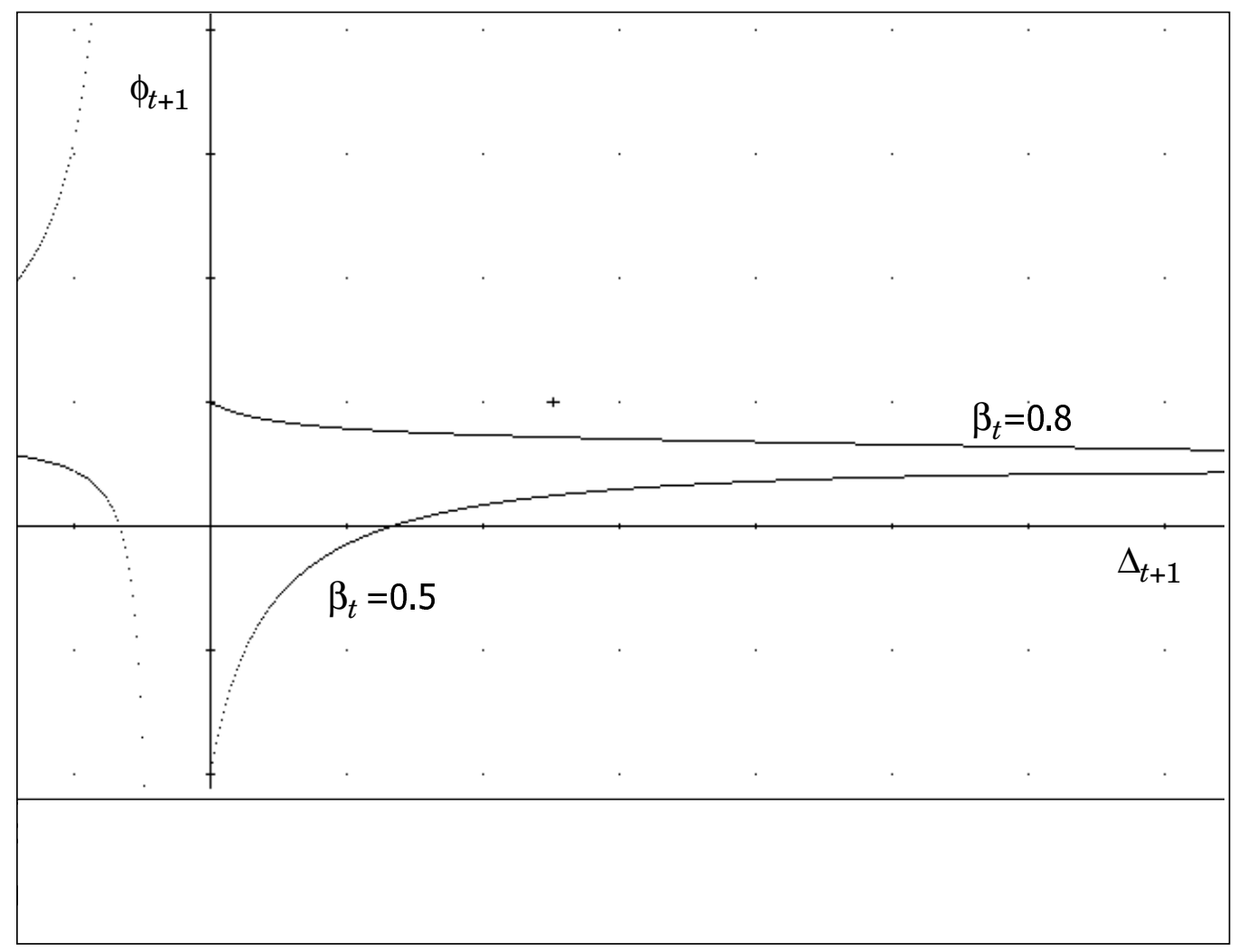


Figure 5

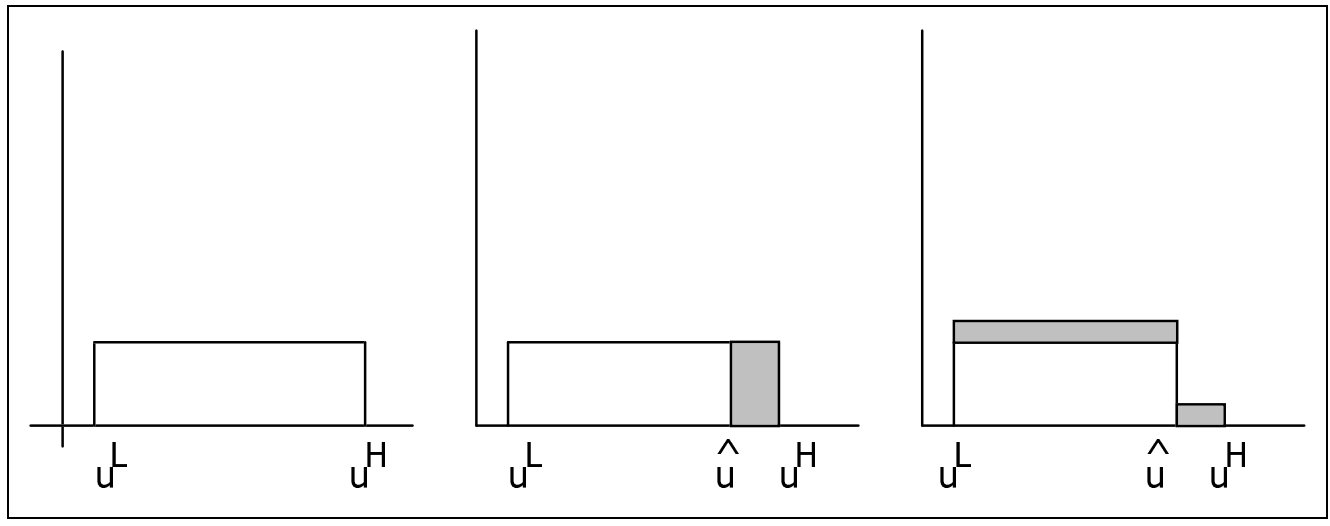



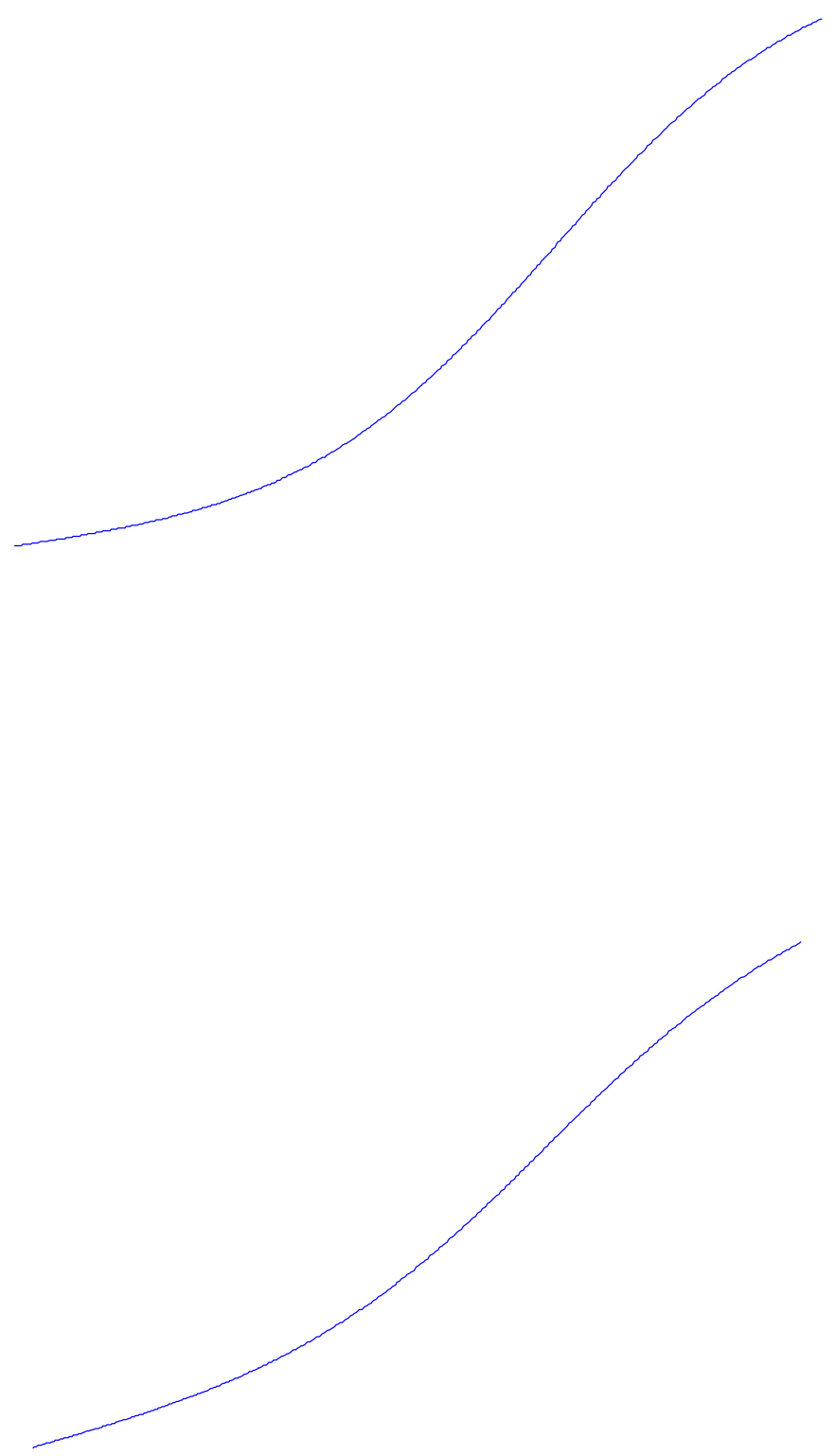

46 


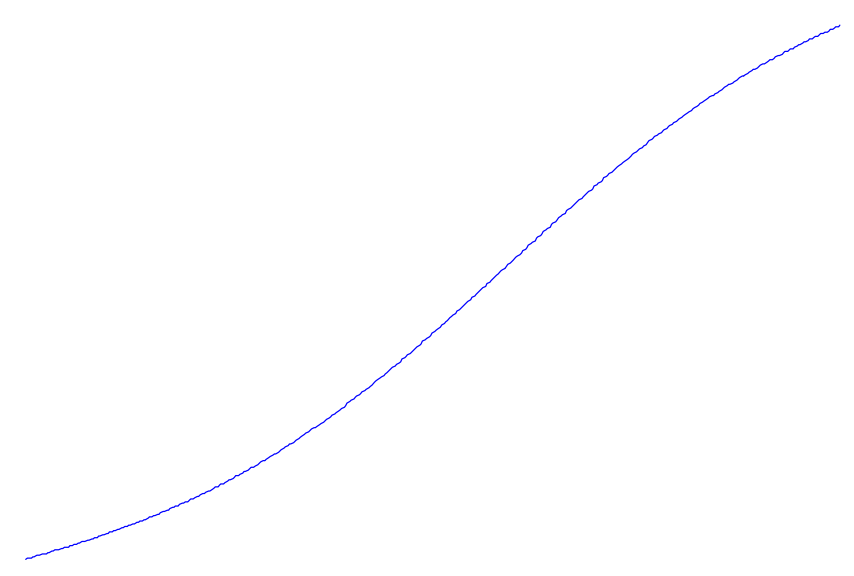




\section{References}

Alchian A. (1950), "Uncertainty, Evolution and Economic Theory", Journal of Political Economy", 58.

Arrow K.J.(1986), "Rationality of Self and Others in an Economic System", in Hogarth R.M., Reder M.W.(eds.), Rational Choice. The Contrast between Economics and Psychology, Chicago University Press, Chicago.

Arthur W.B. (1992), "On Learning and Adaptation in the Economy", Santa Fe Institute Working Paper, no. 92-07-038.

Bray M., Kreps D.M. (1986), "Rational Learning and Rational Expectations", in Feiwel G. (ed.), Arrow and the Ascent of Modern Economic Theory, New York, New York University Press, pp.597625.

Burden, R.L. and Faires, J.D. (1993), Numerical Analysis, Boston, Pws, 5 th edition.

Freixas X., Rochet J.C. (1998), The Microeconomics of Banking, Cambridge (Mass.), The MIT Press.

Friedman M. (1949), Essays in Positive Economics, Chicago, Chicago University Press

Frydman R. (1983), "Individual Rationality, Decentralization, and the Rational Expectations Hypothesis", in Frydman R., Phelps E.(eds.), Individual Forecasting and Aggregate Outcomes, Cambridge, Canbridge University Press.

Greenwald B., Stiglitz J.E. (1988), "Money, Imperfect Information and Economic Fluctuations", in Kohn M., Tsiang S.C. (eds.), Finance Constraints, Expectations and Macroeconomics, Oxford, Oxford University Press.

Greenwald, B.C., Stiglitz, J.E. (1990), "Asymmetric Information and the New Theory of the Firm, Financial Constraints and Risk Behavior", Papers and Proceedings of the American Economic Association, American Economic Review, 80, n.2, 160-165. 
Greenwald, B.C., Stiglitz, J.E. (1993), "Financial market imperfections and business cycles", Quarterly Journal of Economics, 108, 77113.

Hahn F.(1977), "Keynesian Economics and General Equilibrium Theory: Reflections on Some Current Debates", in Harcourt G.C.(ed.), The Microeconomic Foundations of Macroeconomics, London, MacMillan.

Hahn F.(1981), "General Equilibrium Theory", in Bell D., Kristol

Hahn F., Solow R. (1995), A Critical Essay on Modern Macroeconomic Theory, Cambridge Mass., The MIT Press.

Hicks J.R. (1951), "The Disaster Point in the Theory of Risk", in Economic Perspectives, Oxford, Clarendon Press, 1977

Holland J.H. (1975), Adaptation in Natural and Artificial Systems, Ann Arbor, University of Michigan Press.

Kirman A. (1992), "Whom or What Does the Representative Individual Represent?", Journal of Economic Perspectives, vol.6, pp.117-136.

Kirman A. (1987), "The Intrinsic Limits of Modern Economic Theory. The Emperor has no clothes", Economic Journal, vol.97, pp.107121.

Kiyotaki N., Moore J. (1997), «Credit Cycles», Journal of Political Economy, 105, pp. 211-248

Lucas R.E. (1987), "Adaptive Behavior and Economic Theory", in Hogarth R.M., Reder M.W. (eds.), Rational Choice. The Contrast Between Economics and Psychology, Chicago, Chicago University Press.

Marcet A., Sargent T. (1989), "Convergence of Least Squares Learning Mechanisms in Self-Referential Linear Stochastic Models", Journal of Economic Theory, vol.48, pp.337-368.

Pesaran H. M. (1987), The Limits to Rational Expectations, Oxford, Bkackwell.

Roy, A. D. (1952), "Safety First and the Holding of Assets", Econometrica, 20, 431-449. 


\section{Elenco dei papers del Dipartimento di Economia}

1989.1 Knowledge and Prediction of Economic Behaviour: Towards A Constructivist Approach. by Roberto Tamborini.

1989.2 Export Stabilization and Optimal Currency Baskets: the Case of Latin AmericanCountries. by Renzo G.Avesani Giampiero M. Gallo and Peter Pauly.

1989.3 Quali garanzie per i sottoscrittori di titoli di Stato? Una rilettura del rapporto della Commissione Economica dell'Assemblea Costituente di Franco Spinelli e Danilo Vismara.

(What Guarantees to the Treasury Bill Holders? The Report of the Assemblea Costituente Economic Commission Reconsidered by Franco Spinelli and Danilo Vismara.)

1989.4 L'intervento pubblico nell'economia della "Venezia Tridentina" durante l'immediato dopoguerra di Angelo Moioli.

(The Public Intervention in "Venezia Tridentina" Economy in the First War Aftermath by Angelo Moioli.)

1989.5 L'economia lombarda verso la maturità dell'equilibrio agricolo-commerciale durante l'età delle riforme di Angelo Moioli.

(The Lombard Economy Towards the Agriculture-Trade Equilibrium in the Reform Age by Angelo Moioli.)

1989.6 L'identificazione delle allocazioni dei fattori produttivi con il duale di Quirino Paris e di Luciano Pilati. (Identification of Factor Allocations Through the Dual Approach by Quirino Paris and Luciano Pilati.)

1990.1 Le scelte organizzative e localizzative dell'amministrazione postale: un modello intrpretativo di Gianfranco Cerea. 
(The Post Service' s Organizational and Locational Choices: An Interpretative Model by Gianfranco Cerea.)

1990.2 Towards a Consistent Characterization of the Financial Economy. by Roberto Tamborini.

1990.3 Nuova macroeconomia classica ed equilibrio economico generale: considerazioni sulla pretesa matrice walrasiana della N.M.C. di Giuseppe Chirichiello.

(New Classical Macroeconomics and General Equilibrium: Some Notes on the Alleged Walrasian Matrix of the N.C.M.by Giuseppe Chirichiello.)

1990.4 Exchange Rate Changes and Price Determination in Polypolistic Markets. by Roberto Tamborini.

1990.5 Congestione urbana e politiche del traffico. Un' analisi economica di Giuseppe Folloni e Gianluigi Gorla.

(Urban Congestion and Traffic Policy. An Economic Analysis by Giuseppe Folloni and Gianluigi Gorla.)

1990.6 Il ruolo della qualità nella domanda di servizi pubblici. Un metodo di analisi empirica di Luigi Mittone.

(The Role of Quality in the Demand for Public Services. A Methodology for Empirical Analysis by Luigi Mittone.)

1991.1 Consumer Behaviour under Conditions of Incomplete Information on Quality: a Note by Pilati Luciano and Giuseppe Ricci.

1991.2 Current Account and Budget Deficit in an Interdependent World by Luigi Bosco.

1991.3 Scelte di consumo, qualità incerta e razionalità limitata di Luigi Mittone e Roberto Tamborini.

(Consumer Choice, Unknown Quality and Bounded Rationality by Luigi Mittone and Roberto Tamborini.) 
1991.4 Jumping in the Band: Undeclared Intervention Thresholds in a Target Zone by Renzo G. Avesani and Giampiero M. Gallo.

1991.5 The World Tranfer Problem. Capital Flows and the Adjustment of Payments by Roberto Tamborini.

1992.1 Can People Learn Rational Expectations? An Ecological Approach by Pier Luigi Sacco.

1992.2 On Cash Dividends as a Social Institution by Luca Beltrametti.

1992.3 Politica tariffaria e politica informativa nell' offerta di servizi pubblici di Luigi Mittone

(Pricing and Information Policy in the Supply of Public Services by Luigi Mittone.)

1992.4 Technological Change, Technological Systems, Factors of Production by Gilberto Antonelli and Giovanni Pegoretti.

1992.5 Note in tema di progresso tecnico di Geremia Gios e Claudio Miglierina.

(Notes on Technical Progress, by Geremia Gios and Claudio Miglierina).

1992.6 Deflation in Input Output Tables by Giuseppe Folloni and Claudio Miglierina.

1992.7 Riduzione della complessità decisionale: politiche normative e produzione di informazione di Luigi Mittone (Reduction in decision complexity: normative policies and information production by Luigi Mittone)

1992.8 Single Market Emu and Widening. Responses to Three Institutional Shocks in the European Community by Pier Carlo Padoan and Marcello Pericoli

1993.1 La tutela dei soggetti "privi di mezzi": Criteri e procedure per la valutazione della condizione economica di 
Gianfranco Cerea (Public policies for the poor: criteria and procedures for a novel means test by Gianfranco Cerea )

1993.2 La tutela dei soggetti "privi di mezzi": un modello matematico per la rappresentazione della condizione economica di Wolfgang J. Irler

(Public policies for the poor: a mathematical model for a novel means test by Wolfgang J.Irler)

1993.3 Quasi-markets and Uncertainty: the Case of General Proctice Service by Luigi Mittone

1993.4 Aggregation of Individual Demand Functions and Convergence to Walrasian Equilibria by Dario Paternoster

1993.5 A Learning Experiment with Classifier System: the Determinants of the Dollar-Mark Exchange Rate by Luca Beltrametti, Luigi Marengo and Roberto Tamborini

1993.6 Alcune considerazioni sui paesi a sviluppo recente di Silvio Goglio (Latecomer Countries: Evidence and Comments by Silvio Goglio)

1993.7 Italia ed Europa: note sulla crisi dello SME di Luigi Bosco (Italy and Europe: Notes on the Crisis of the EMS by Luigi Bosco)

1993.8 Un contributo all' analisi del mutamento strutturale nei modelli input-output di Gabriella Berloffa

(Measuring Structural Change in Input-Output Models: a Contribution by Gabriella Berloffa)

1993.9 On Competing Theories of Economic Growth: a Crosscountry Evidence by Maurizio Pugno

1993.10 Le obbligazioni comunali di Carlo Buratti (Municipal Bonds by Carlo Buratti)

1993.11 Due saggi sull' organizzazione e il finanziamento della scuola statale di Carlo Buratti (Two Essays on the 
Organization and Financing of Italian State Schools by Carlo Buratti

1994.1 Un' interpretazione della crescita regionale: leaders, attività indotte e conseguenze di policy di Giuseppe Folloni e Silvio Giove.

(A Hypothesis about regional Growth: Leaders, induced Activities and Policy by Giuseppe Folloni and Silvio Giove).

1994.2 Tax evasion and moral constraints: some experimental evidence by Luigi Bosco and Luigi Mittone.

1995.1 A Kaldorian Model of Economic Growth with Shortage of Labour and Innovations by Maurizio Pugno.

1995.2 A che punto è la storia d'impresa? Una riflessione storiografica e due ricerche sul campo a cura di Luigi Trezzi.

1995.3 Il futuro dell' impresa cooperativa: tra sistemi, reti ed ibridazioni di Luciano Pilati.

(The future of the cooperative enterprise: among systems, networks and hybridisation by Luciano Pilati).

1995.4 Sulla possibile indeterminatezza di un sistema pensionistico in perfetto equilibrio finanziario di Luca Beltrametti e Luigi Bonatti.

(On the indeterminacy of a perfectly balanced social security system by Luca Beltrametti and Luigi Bonatti).

1995.5 Two Goodwinian Models of Economic Growth for East Asian NICs by Maurizio Pugno.

1995.6 Increasing Returns and Externalities: Introducing Spatial Diffusion into Krugman's Economic Geographyby Giuseppe Folloni and Gianluigi Gorla.

1995.7 Benefit of Economic Policy Cooperation in a Model with Current Account Dynamics and Budget Deficit by Luigi Bosco. 
1995.8 Coalition and Cooperation in Interdependent Economies by Luigi Bosco.

1995.9 La finanza pubblica italiana e l' ingresso nell' unione monetaria europea di Ferdinando Targetti. (Italian Public Finance and the Entry in the EMU by Ferdinando Targetti)

1996.1 Employment, Growth and Income Inequality: some open Questions by Annamaria Simonazzi and Paola Villa.

1996.2 Keynes' Idea of Uncertainty: a Proposal for its Quantification by Guido Fioretti.

1996.3 The Persistence of a "Low-Skill, Bad-Job Trap" in a Dynamic Model of a Dual Labor Market by Luigi Bonatti.

1996.4 Lebanon: from Development to Civil War by Silvio Goglio.

1996.5 A Mediterranean Perspective on the Break-Down of the Relationship between Participation and Fertility by Francesca Bettio and Paola Villa.

1996.6 Is there any persistence in innovative activities? by Elena Cefis.

1997.1 Imprenditorialità nelle alpi fra età moderna $e$ contemporanea a cura di Luigi Trezzi.

1997.2 Il costo del denaro è uno strumento anti-inflazionistico? di Roberto Tamborini. (Is the Interest Rate an AntiInflationary Tool? by Roberto Tamborini).

1997.3 A Stability Pact for the EMU? by Roberto Tamborini.

1997.4 Mr Keynes and the Moderns by Axel Leijonhufvud.

1997.5 The Wicksellian Heritage by Axel Leijonhufvud.

1997.6 On pension policies in open economies by Luca Beltrametti and Luigi Bonatti. 
1997.7 The Multi-Stakeholders Versus the Nonprofit Organisation by Carlo Borzaga and Luigi Mittone.

1997.8 How can the Choice of a Tme-Consistent Monetary Policy have Systematic Real Effects? by Luigi Bonatti.

1997.9 Negative Externalities as the Cause of Growth in a Neoclassical Model by Stefano Bartolini and Luigi Bonatti.

1997.10 Externalities and Growth in an Evolutionary Game by Angelo Antoci and Stefano Bartolini.

1997.11 An Investigation into the New Keynesian Macroeconomics of Imperfect Capital Markets by Roberto Tamborini.

1998.1 Assessing Accuracy in Transition Probability Matrices by Elena Cefis and Giuseppe Espa.

1998.2 Microfoundations: Adaptative or Optimizing? by Axel Leijonhufvud.

1998.3 Clower's intellectual voyage: the 'Ariadne's thread' of continuity through changes by Elisabetta De Antoni.

1998.4 The Persistence of Innovative Activities. A CrossCountries and Cross-Sectors Comparative Analysis by Elena Cefis and Luigi Orsenigo

1998.5 Growth as a Coordination Failure by Stefano Bartolini and Luigi Bonatti

1998.6 Monetary Theory and Central Banking by Axel Leijonhufvud

1998.7 Monetary policy, credit and aggregate supply: the evidence from Italy by Riccardo Fiorentini and Roberto Tamborini

1998.8 Stability and multiple equilibria in a model of talent, rent seeking, and growth by Maurizio Pugno 
1998.9 Two types of crisis by Axel Leijonhufvud

1998.10 Trade and labour markets: vertical and regional differentiation in Italy by Giuseppe Celi e Maria Luigia Segnana

1998.11 Utilizzo della rete neurale nella costruzione di un trading system by Giulio Pettenuzzo

1998.12 The impact of social security tax on the size of the informal economy by Luigi Bonatti

1999.1 L'economia della montagna interna italiana: un approccio storiografico, a cura di Andrea Leonardi e Andrea Bonoldi.

1999.2 Unemployment risk, labour force participation and savings, by Gabriella Berloffa e Peter Simmons

1999.3 Economia sommersa, disoccupazione e crescita, by Maurizio Pugno

1999.4 The nationalisation of the British Railways in Uruguay, by Giorgio Fodor

1999.5 Elements for the history of the standard commodity, by Giorgio Fodor

1999.6 Financial Market Imperfections, Heterogeneity and growth, by Edoardo Gaffeo

1999.7 Growth, real interest, employment and wage determination, by Luigi Bonatti

2000.1 A two-sector model of the effects of wage compression on unemployment and industry distribution of employment, by Luigi Bonatti

2000.2 From Kuwait to Kosovo: What have we learned? Reflections on globalization and peace, by Roberto Tamborini 2000.3 Metodo e valutazione in economia. Dall'apriorismo a Friedman , by Matteo Motterlini 
2000.4 Under tertiarisation and unemployment. by Maurizio Pugno

2001.1 Growth and Monetary Rules in a Model with Competitive Labor Markets, by Luigi Bonatti.

2001.2 Profit Versus Non-Profit Firms in the Service Sector: an Analysis of the Employment and Welfare Implications, by Luigi Bonatti, Carlo Borzaga and Luigi Mittone.

2001.3 Statistical Economic Approach to Mixed Stock-Flows Dynamic Models in Macroeconomics, by Bernardo Maggi and Giuseppe Espa.

2001.4 The monetary transmission mechanism in Italy: The credit channel and a missing ring, by Riccardo Fiorentini and Roberto Tamborini.

2001.5 Vat evasion: an experimental approach, by Luigi Mittone

2001.6 Decomposability and Modularity of Economic Interactions, by Luigi Marengo, Corrado Pasquali and Marco Valente.

2001.7 Unbalanced Growth and Women's Homework, by Maurizio Pugno

2002.1 The Underground Economy and the Underdevelopment Trap, by Maria Rosarua Carillo and Maurizio Pugno

2002.2 Interregional Income Redistribution and Convergence in a Model with Perfect Capital Mobility and Unionized Labor Markets, by Luigi Bonatti

2002.3 Firms' bankruptcy and turnover in a macroeconomy, by Marco Bee, Giuseppe Espa and Roberto Tamborini 
PUBBLICAZIONE REGISTRATA PRESSO IL TRIBUNALE DI TRENTO 59 
